\title{
UK Renal Registry 16th Annual Report: Chapter 8 Survival and Cause of Death of UK Adult Patients on Renal Replacement Therapy in 2012: National and Centre-specific Analyses
}

\author{
Rishi Pruthi, Retha Steenkamp, Terry Feest \\ UK Renal Registry, Bristol, UK
}

\section{Key Words}

Cause of death . Comorbidity - Dialysis - End stage renal disease - Established renal failure - Haemodialysis - Median life expectancy . Outcome . Peritoneal dialysis - Renal replacement therapy (RRT) · Survival · Transplant · Vintage

\footnotetext{
Abstract

Introduction: These analyses examine: a) survival from the start of renal replacement therapy (RRT); b) survival amongst all prevalent dialysis patients alive on 31st December 2011; c) the cause of death for incident and prevalent patients and d) the projected life years remaining for patients starting RRT. Changes in survival between the 1997 and 2011 cohort are also reported. Methods: Survival was calculated for both incident and prevalent patients on RRT. Survival of incident patients (starting RRT during 2011) was calculated both from the start of RRT and from 90 days after starting RRT, both with and without censoring at transplantation. Prevalent dialysis patients were censored at transplantation. Both
}

Kaplan-Meier and Cox adjusted models were used to calculate survival. The relative risk of death was calculated and compared with the UK general population. Results: The unadjusted 1 year after 90 day survival for patients starting RRT in 2011 was $87.5 \%$, representing an increase from the previous year (87.3\%). The age-adjusted one year survival (adjusted to age 60) of prevalent dialysis patients increased from $88.2 \%$ in the 2002 cohort to $89.7 \%$ in the 2011 cohort. Prevalent diabetic patient one year survival rose from $81.6 \%$ in the 2002 cohort to $84.9 \%$ in the 2011 cohort. The age-standardised mortality ratio for prevalent RRT patients compared with the general population was 16.6 for age group 35-39 and 2.7 at age $85+$ years. In the prevalent RRT dialysis population, cardiovascular disease accounted for $22 \%$ of deaths, infection $17 \%$ and treatment withdrawal $19 \%$. The median life years remaining for a 25-29 year old on RRT was 18.5 years and approximately 2.5 for a $75+$ year old. Conclusions: Survival of patients starting RRT has improved in the 2011 incident cohort. The relative risk of death on RRT compared with the general population has fallen since 2001.

$\begin{array}{ll}\text { KARGER } & \text { C } 2014 \mathrm{~S} . \text { Karger AG, Basel } \\ \text { Fax +4161306 1234 } & 1160-2110 / 14 / 1254-0139 \$ 38.00 / 0 \\ \begin{array}{l}\text { E-Mail karger@karger.com } \\ \text { www.karger.com }\end{array} & \begin{array}{l}\text { Accessible online at: } \\ \text { www.karger.com/nec }\end{array}\end{array}$

Rishi Pruthi

UK Renal Registry, Southmead Hospital, Southmead Road, Bristol, BS10 5NB, UK

Email: renalregistry@renalregistry.nhs.uk 


\section{Introduction}

The analyses presented in this chapter examine: a) survival from the start of renal replacement therapy (RRT) of adults; b) survival amongst all prevalent adult dialysis patients alive on 31st December 2011; c) the cause of death for incident and prevalent adult patients and d) the projected life years remaining for adult patients starting RRT. They encompass the outcomes from the total incident adult UK dialysis population reported to the UK Renal Registry (UKRR), including the $19.5 \%$ who started on peritoneal dialysis and the $7 \%$ who received a pre-emptive renal transplant. These results are therefore a true reflection of the outcomes in the whole UK adult RRT population. Analyses of survival within the first year of starting RRT include patients who were recorded as having started RRT for established renal failure (as opposed to acute kidney injury) but who had died within the first 90 days of starting RRT, a group excluded from most other countries' registry data. As is common in other countries, survival analyses are also presented for the first year after 90 days.

The term established renal failure (ERF) used throughout this chapter is synonymous with the terms end stage renal failure (ESRF) and end stage renal disease (ESRD) which are in more widespread international usage. Within the UK, patients have disliked the term 'end stage'; the term ERF was endorsed by the English National Service Framework for Renal Services, published in 2004.

The prevalent dialysis patient group was defined as all patients over 18 years old, alive and receiving dialysis on 31st December 2011 who had been on dialysis for at least 90 days at one of the UK adult renal centres.

Since 2006, the UKRR has openly reported and published centre attributable RRT survival data. It is again stressed that these are raw data which continue to require very cautious interpretation. The UKRR can adjust for the effects of the different age distributions of patients in different centres, but lacks sufficient data from many participating centres to enable adjustment for primary renal diagnosis, other comorbidities at start of RRT (age and comorbidity, especially diabetes, are major factors associated with survival [1-3]) and ethnic origin, which have been shown to have an impact on outcome (for instance, better survival is expected in centres with a higher proportion of Black and South Asian patients) [4]. This lack of information on casemix makes interpretation of any apparent difference in survival between centres difficult. Despite the uncertainty about any apparent differences in outcome, for centres which appear to be outliers the UKRR will follow the clinical governance procedures as set out in chapter 2 of the 2009 UKRR Report [5].

\section{Methods}

The unadjusted survival probabilities (with 95\% confidence intervals) were calculated using the Kaplan-Meier method, in which the probability of surviving more than a given time can be estimated for members of a cohort of patients, without any adjustment for age or other factors that affect the chances of survival. Where centres are small, or the survival probabilities are greater than $90 \%$, the confidence intervals are only approximate.

In order to estimate the difference in survival of different subgroups of patients within the cohort, a stratified proportional hazards model (Cox) was used where appropriate. The results from the Cox model were interpreted using a hazard ratio. When comparing two groups, the hazard ratio is the ratio of the estimated hazard for group A relative to group B, where the hazard is the risk of dying at time $t$ given that the individual has survived until this time. The underlying assumption of a proportional hazards model is that the hazard ratio remains constant throughout the period under consideration. Whenever used, the assumptions of the proportional hazards model were tested.

To allow comparisons between centres with differing age distributions, survival analyses were statistically adjusted for age and reported as survival adjusted to age 60 . This gives an estimate of what the survival would have been if all patients in that centre had been aged 60 at the start of RRT. This age was chosen because it was approximately the average age of patients starting RRT 15 years ago at the start of the UKRR's data collection. The average age of patients commencing RRT in the UK has been stable recently around an age of 62 years, but the UKRR has maintained age adjustment to 60 years for comparability with all previous years' analyses. Diabetic patients were included in all analyses unless stated otherwise, and in many analyses diabetic patients were also analysed separately and compared to non-diabetic patients. All analyses were undertaken using SAS 9.3.

\section{Definition of renal replacement therapy start date}

The incident survival figures quoted in this chapter are from the first day of renal replacement therapy whether with dialysis or a pre-emptive transplant. In the UKRR all patients starting RRT for ERF are included from the date of the first RRT treatment wherever it took place (a date currently defined by the clinician) if the clinician considered the renal failure irreversible. Should a patient recover renal function within 90 days they were then excluded. These UK data therefore may include some patients who died within 90 days who had developed acute potentially reversible renal failure but were recorded by the clinician as being in irreversible established renal failure.

Previously, the UKRR asked clinicians to re-enter a code for established renal failure in patients initially coded as having acute renal failure once it had become clear that there was no 
recovery of kidney function. However, adherence to this requirement was very variable, with some clinicians entering a code for established renal failure only once a decision had been made to plan for long-term RRT [6]. All UK nephrologists have now been asked to record the date of the first haemodialysis session and to record whether the patient was considered to have acute kidney injury (acute renal failure) or to be in ERF at the time. For patients initially categorised as 'acute', but who were subsequently categorised as ERF, the UKRR assigns the date of this first 'acute' session as the date of start of RRT.

UKRR analyses of electronic data extracted for the immediate month prior to the start date of RRT provided by clinicians highlighted additional inconsistencies in the definition of this first date when patients started on peritoneal dialysis, with the date of start reported to the UKRR being later than the actual date of start. These findings are described in detail in chapter 13 of the 2009 Report [6]. This concern is unlikely to be unique to the UK, but will be common to analyses from all renal centres and registries.

In addition to these problems of defining day 0 within one country, there is international variability on when patient data are collected by national registries with some countries (often for financial re-imbursement or administrative reasons) defining the 90th day after starting RRT as day 0, whilst others collect data only on those who have survived 90 days and report as zero the number of patients dying within the first 90 days.

Thus as many other national registries do not include reports on patients who do not survive the first 90 days, survival from 90 days onwards is also reported to allow international comparisons. This distinction is important, as there is a much higher death rate in the first 90 days, which would distort comparisons.

\section{Methodology for incident patient survival}

Patients were considered 'incident' at the time of their first RRT, thus patients re-starting dialysis after a failed transplant were not included.

Some patients recover renal function after more than 90 days but subsequently returned to RRT. If recovery was for less than 90 days, the start of renal replacement therapy was calculated from the date of the first episode and the recovery period ignored. If recovery was for 90 days or more, the length of time on RRT was calculated from the day on which the patient restarted RRT.

The incident survival cohort was NOT censored at the time of transplantation and therefore included the survival of the $7 \%$ who received a pre-emptive transplant. An additional reason for not censoring was to facilitate comparison between centres. Centres with a high proportion of patients of South Asian and Black origin are likely to have a healthier dialysis population, because South Asian and Black patients are less likely to undergo early transplantation [7], and centres with a high pre-emptive transplant rate are likely to have a less healthy dialysis population as transplantation selectively removes fit patients only.

The incident ('take-on') population in any specific year excludes those who recovered within 90 days from the start of RRT, but includes patients who recovered from ERF after 90 days. For survival analyses, patients newly transferred into a centre who were already on RRT were excluded from the incident population for that centre and were counted at the centre at which they started RRT.
The one year incident survival is for patients who started RRT from 1st October 2010 until the 30th September 2011 and followed up for one full year (e.g. patients starting RRT on 1st December 2010 were followed through to 30th November 2011). The 2012 incident patients could not be analysed as they had not yet been followed for a sufficient length of time.

For analysis of 1 year after 90 day survival, patients who started RRT from 1st October 2010 until 30th September 2011 were included in the cohort and they were followed up for a full one year after 90 days.

To help identify any centre differences in survival from the small centres (where confidence intervals are large), an analysis of 1 year after 90 day survival using a rolling four year combined incident cohort from 2008 to 2011 was also undertaken. For those centres which had joined the UKRR after 2008, data were not available for all the years but the available data were included.

The death rate per 1,000 patient years was calculated by dividing the number of deaths by the person years exposed. Person years exposed are the total days at risk for each patient (until death, recovery or lost to follow-up) expressed as years. All patients, even those who died within the first 90 days of RRT, were included in the death rate calculation.

Adjustment of 1 year after 90 day survival for the effect of comorbidity was undertaken using a rolling five year combined incident cohort from 2007 to 2011. Twenty-one centres returned $>85 \%$ of comorbidity data for patients in the combined cohort. Adjustment was first performed to a mean age of 60 years, then to the average distribution of primary diagnoses for all 21 centres. The individual centre data were then further adjusted for average distribution of comorbidity present at these centres. The survival hazard function was calculated as the probability of dying in a short time interval considering survival to that interval.

\section{Methodology for prevalent dialysis patient survival}

For prevalent dialysis patients, all patients who had been established on dialysis for at least 90 days on 31st December 2011 were included in these analyses. Prevalent dialysis patients on 31st December 2011 were followed up in 2012 and were censored at transplantation. When a patient is censored at transplantation, this means that the patient is considered as alive up to the point of transplantation, but the patient's status posttransplant is not considered.

As discussed in previous reports, comparison of survival of prevalent dialysis patients between centres is complex. Survival of prevalent dialysis patients can be studied with or without censoring at transplantation and it is common practice in some registries to censor at transplantation. Censoring could cause apparent differences in survival between those renal centres with a high transplant rate and those with a low transplant rate, especially in younger patients where the transplant rate is highest. Censoring at transplantation systematically removes younger fitter patients from the survival data. The differences are likely to be small due to the relatively small proportion of patients being transplanted in a given year compared to the whole dialysis population (about $22 \%$ of the dialysis population aged under 65 and $3 \%$ of the population aged 65 years and over). To allow comparisons with other registries the survival results for prevalent dialysis patients CENSORED for transplantation have been quoted. To understand survival of patients, including 
survival following transplantation, the incident patient analyses should be viewed.

Methodology of cause of death

The EDTA-ERA Registry codes for cause of death were used. These have been grouped into the following categories:

- Cardiac disease

- Cerebrovascular disease

- Infection

- Malignancy

- Treatment withdrawal

- Other

- Uncertain

Some centres had high completeness of data returns to the UKRR for cause of death, whilst others returned no information. Completeness of cause of death data was calculated for all prevalent patients on RRT that died in a specific year with cause of death data completed for that year.

Adult patients aged 18 years and over from England, Wales, Scotland and Northern Ireland were included in the analyses of cause of death. The incident patient analysis included all patients starting RRT in the years 2000-2011. Analysis of prevalent patients included all those aged over 18 years and receiving RRT on 31st December 2011. The death rate was calculated for the UK general population (data from the Office of National Statistics) by age group and compared with the same age group for prevalent patients on RRT on 31st December 2011.

Methodology of median life expectancy (life table calculations)

Kaplan Meier survival analyses were used to calculate the hazard of death by age group $(18-34,35-44,45-54,55-64$, 65-74, 75+) for incident patients starting RRT from 2000-2009, with at least three years follow-up from 2010 to 2012. The patient inclusion criteria are the same to that of the incident patient cohort described above. Patients were followed until death, censoring (recovery or lost to follow-up) or the end of the study period. Life expectancy which gives the probability of surviving until the next time period was calculated as: 1 - hazard of death. Median life years remaining is then the difference between the age when reaching the $50 \%$ probability of survival and the age of starting RRT.

Methodology for comparing mortality in prevalent $R R T$ patients with the mortality in the general population

Data on the UK population in mid-2012 and the number of deaths in each age group in 2012 were obtained from the Office of National Statistics. The age specific UK death rate was calculated as the number of deaths in the UK per thousand people in the population. The age specific expected number of deaths in the RRT population was calculated by applying the UK age specific death rate to the total of years exposed for RRT patients in that age group. This is expressed as deaths per 1,000 patient years. The age specific number of RRT deaths is the actual number of deaths observed in 2012 in RRT patients. The RRT observed death rate was calculated as number of deaths observed in 2012 per 1,000 patient years exposed. Relative risk of death was calculated as the ratio of the observed and expected death rates for RRT patients.

\section{Results of incident (new RRT) patient survival}

The 2011 incident cohort included 6,750 patients who started RRT, without any period of renal function recovery lasting more than 90 days. The unadjusted 1 year after 90 day survival for incident patients starting RRT in 2011 (table 8.1 ) has increased to $87.5 \%$ compared to $87.3 \%$ in the 2010 cohort.

\section{Comparison of survival between UK countries}

Two years incident data have been combined to increase the size of the patient cohort, so that any differences between the four UK countries are more likely to be reliably identified (table 8.2). These data have not been adjusted for differences in primary renal diagnosis, ethnicity, socio-economic status or comorbidity, nor for differences in life expectancy in the general populations of the four UK countries. There was no significant difference in the 90 day survival between the UK countries. One year after 90 day survival was significantly lower in Wales compared to England. It has been postulated that a greater prevalence of cardiovascular disease in Wales compared to England may account for the difference.

There are known regional differences in the life expectancy of the general population within the UK. Table 8.3 shows differences in life expectancy between the UK countries. These differences in life expectancy are not accounted for in these analyses and are likely to be one of the reasons behind the variation in survival between renal centres and UK countries.

\section{Modality}

It is impossible to obtain truly valid comparisons of survival of patients starting RRT on different treatment modalities, as modality selection is not random. In the $\mathrm{UK}$, patients starting peritoneal dialysis as a group were younger and fitter than those starting haemodialysis and were transplanted more quickly. The age adjusted 1 year survival estimates for incident patients starting RRT on HD and PD were $89.3 \%$ and $92.9 \%$ respectively, both showing a slight increase from the previous year (figure 8.1, table 8.4). Over the last six years the one

Table 8.1. Unadjusted survival of incident patients, 2011 cohort

\begin{tabular}{lccc}
\hline Interval & $\begin{array}{c}\text { Survival } \\
(\%)\end{array}$ & $95 \% C I$ & $N$ \\
\hline Survival at 90 day & 94.5 & $93.9-95.0$ & 6,750 \\
Survival 1 year after 90 days & 87.5 & $86.7-88.3$ & 6,359 \\
\hline
\end{tabular}


Table 8.2. Incident patient survival across the UK countries, combined 2 year cohort (2010-2011), adjusted to age 60

\begin{tabular}{|c|c|c|c|c|c|}
\hline Interval & England & $\mathrm{N}$ Ireland & Scotland & Wales & UK \\
\hline $95 \% C I$ & $95.8-96.6$ & $94.4-97.7$ & $94.7-96.8$ & $95.6-97.7$ & $95.8-96.5$ \\
\hline $95 \% C I$ & $89.9-91.1$ & $87.7-93.1$ & $87.1-90.7$ & $86.1-90.3$ & $89.7-90.9$ \\
\hline
\end{tabular}

Table 8.3. Life expectancy in years in UK countries, 2008-2010 (source ONS [8])

\begin{tabular}{lccccc}
\hline \multirow{2}{*}{ Country } & \multicolumn{2}{c}{ At birth } & & \multicolumn{2}{c}{ At age 65 } \\
\cline { 2 - 3 } \cline { 6 - 6 } \cline { 5 - 6 } & Male & Female & & Male & Female \\
\hline England & 78.6 & 82.6 & & 18.2 & 20.8 \\
Northern Ireland* & 77.1 & 81.5 & & 17.4 & 20.2 \\
Scotland & 75.8 & 80.4 & & 16.8 & 19.3 \\
Wales & 77.6 & 81.8 & & 17.7 & 20.3 \\
UK & $\mathbf{7 8 . 2}$ & $\mathbf{8 2 . 3}$ & & $\mathbf{1 8 . 0}$ & $\mathbf{2 0 . 6}$ \\
\hline
\end{tabular}

${ }^{*}$ Provisional data for Northern Ireland

year after 90 days survival has progressively improved in $\mathrm{HD}$ patients, but remained static in $\mathrm{PD}$ patients (table 8.4).

\section{Age}

Tables 8.5 to 8.10 show survival of all incident patients, those aged 65 and above and those aged below 65 years, for up to ten years after start of renal replacement therapy. In the UK, short term survival (survival at 90 days) increased to $94.5 \%$ ( $94.2 \%$ for patients starting RRT in 2010) (table 8.5). Survival 1 year after 90 days also increased compared to last year and this was mainly due to an increase in survival for patients aged younger than 65 years (table 8.6). Longer term survival of patients on RRT continued to improve (tables 8.8, 8.9, 8.10).
Table 8.4. One year after 90 day incident patient survival by first established modality 2005-2011 cohort (adjusted to age 60) (excluding patients whose first modality was transplantation)

\begin{tabular}{lcc}
\hline & \multicolumn{2}{c}{ Age adjusted 1 year after 90 days \% survival } \\
& \multicolumn{2}{c}{$95 \%$ CI } \\
\cline { 2 - 3 } Year & HD & PD \\
\hline 2011 & 89.3 & 92.9 \\
& $88.3-90.3$ & $91.6-94.3$ \\
2010 & 87.7 & 93.3 \\
& $86.6-88.8$ & $91.9-94.7$ \\
2009 & 87.6 & 93.1 \\
& $86.5-88.7$ & $91.6-94.6$ \\
2008 & 87.1 & 93.1 \\
& $86.0-88.2$ & $91.7-94.4$ \\
2007 & 87.8 & 94.5 \\
& $86.7-88.9$ & $93.3-95.7$ \\
2006 & 86.5 & 94.1 \\
& $85.4-87.7$ & $92.8-95.4$ \\
2005 & 85.3 & 92.5 \\
& $84.0-86.5$ & $91.1-94.0$ \\
\hline
\end{tabular}

There is a steep decline in survival with advancing age (figures 8.2 and 8.3).

There was a curvilinear increase in death rate per 1,000 patient years with age, shown in figure 8.3 for the period one year after 90 days. There were differences between the overall death rates across all age groups with the

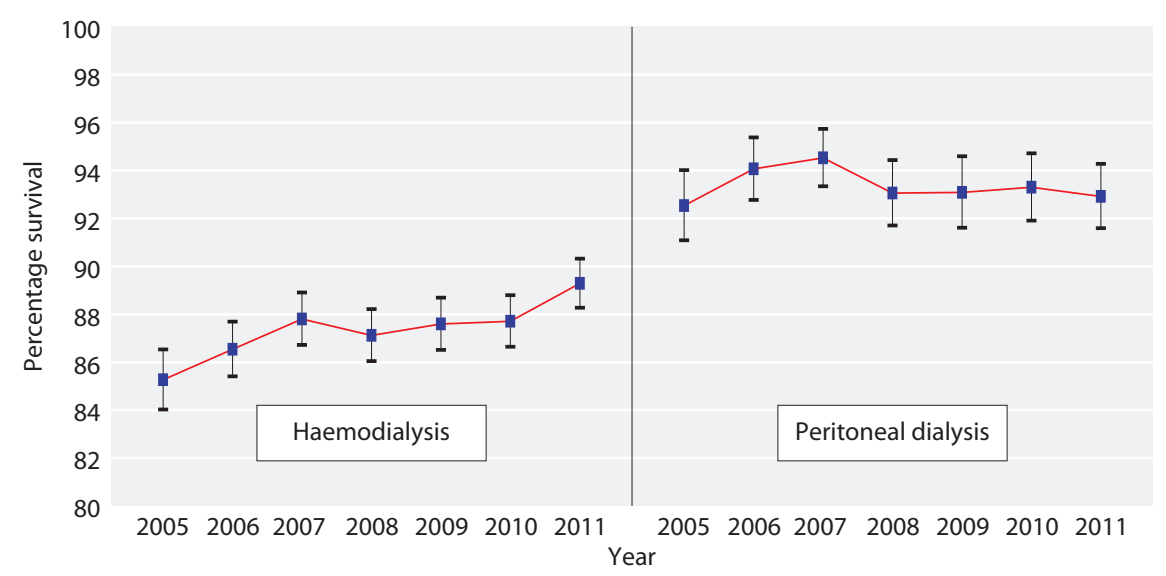

Fig. 8.1. Trend in 1 year after 90 day incident patient survival by first modality, 2005-2011 cohort (adjusted to age 60) (excluding patients whose first modality was transplantation) 
Table 8.5. Unadjusted 90 day survival of incident patients, 2011 cohort, by age

\begin{tabular}{lccc}
\hline Age & Survival (\%) & $95 \%$ CI & $N$ \\
\hline $18-64$ & 97.8 & $97.2-98.2$ & 3,370 \\
65 & 91.2 & $90.2-92.1$ & 3,380 \\
All ages & 94.5 & $93.9-95.0$ & 6,750 \\
\hline
\end{tabular}

death rate in Scotland and Wales significantly higher than in England.

The effect of censoring age related survival at the time of transplantation

The current method for calculating survival for incident patients does not censor at transplantation. From
Table 8.6. Unadjusted 1 year after day 90 survival of incident patients, 2011 cohort, by age

\begin{tabular}{lccc}
\hline Age & Survival (\%) & $95 \% C I$ & $N$ \\
\hline $18-64$ & 94.1 & $93.2-94.8$ & 3,284 \\
65 & 80.6 & $79.1-82.0$ & 3,075 \\
All ages & 87.5 & $86.7-88.3$ & 6,359 \\
\hline
\end{tabular}

Table 8.7. Increase in proportional hazard of death for each 10 year increase in age, 2011 incident cohort

\begin{tabular}{lcc}
\hline Interval & $\begin{array}{c}\text { Hazard of death for } \\
\text { 10 year age increase }\end{array}$ & $95 \%$ CI \\
\hline First 90 days & 1.70 & $1.56-1.85$ \\
1 year after first 90 days & 1.64 & $1.55-1.73$ \\
\hline
\end{tabular}

Table 8.8. Unadjusted survival of incident patients, 1997-2011 cohort for patients aged 18-64

\begin{tabular}{|c|c|c|c|c|c|c|c|c|c|c|c|c|}
\hline Cohort & 1 year & 2 year & 3 year & 4 year & 5 year & 6 year & 7 year & 8 year & 9 year & 10 year & $\begin{array}{l}95 \% \text { CI for } \\
\text { latest year }\end{array}$ & $N$ \\
\hline 2011 & 93.4 & & & & & & & & & & $92.5-94.2$ & 3,370 \\
\hline 2009 & 91.3 & 85.4 & 80.8 & & & & & & & & $79.4-82.2$ & 3,160 \\
\hline 2008 & 91.6 & 86.2 & 81.4 & 77.3 & & & & & & & $75.8-78.6$ & 3,481 \\
\hline 2007 & 92.7 & 87.2 & 82.0 & 77.1 & 73.4 & & & & & & $71.8-74.8$ & 3,347 \\
\hline 2004 & 89.7 & 83.6 & 78.2 & 72.8 & 68.2 & 64.5 & 61.5 & 57.7 & & & $55.7-59.6$ & 2,571 \\
\hline 2003 & 89.5 & 82.8 & 77.5 & 72.6 & 67.6 & 63.5 & 59.8 & 57.0 & 54.4 & & $52.3-56.5$ & 2,271 \\
\hline 2002 & 88.7 & 80.9 & 74.9 & 69.4 & 65.3 & 61.4 & 58.0 & 55.1 & 52.0 & 49.9 & $47.7-52.1$ & 2,034 \\
\hline 2001 & 88.3 & 81.3 & 75.5 & 70.5 & 65.3 & 60.6 & 56.5 & 53.0 & 50.2 & 48.2 & $45.7-50.7$ & 1,611 \\
\hline 2000 & 89.2 & 81.4 & 74.6 & 69.3 & 64.0 & 59.4 & 55.9 & 52.7 & 50.3 & 47.6 & $45.0-50.1$ & 1,533 \\
\hline 1999 & 87.0 & 81.1 & 73.4 & 67.6 & 62.2 & 58.1 & 54.0 & 51.1 & 48.7 & 47.1 & $44.4-49.8$ & 1,349 \\
\hline
\end{tabular}

Table 8.9. Unadjusted survival of incident patients, 1997-2011 cohort for patients aged 65

\begin{tabular}{|c|c|c|c|c|c|c|c|c|c|c|c|c|}
\hline Cohort & 1 year & 2 year & 3 year & 4 year & 5 year & 6 year & 7 year & 8 year & 9 year & 10 year & $\begin{array}{l}95 \% \text { CI for } \\
\text { latest year }\end{array}$ & $N$ \\
\hline 2011 & 77.5 & & & & & & & & & & $76.1-78.9$ & 3,380 \\
\hline 2009 & 76.9 & 63.8 & 52.8 & & & & & & & & $51.1-54.6$ & 3,147 \\
\hline 2008 & 74.8 & 61.5 & 50.3 & 40.9 & & & & & & & $39.2-42.6$ & 3,184 \\
\hline 2007 & 75.3 & 61.5 & 50.2 & 41.0 & 32.5 & & & & & & $30.9-34.1$ & 3,221 \\
\hline 2004 & 69.3 & 54.4 & 43.0 & 34.6 & 27.4 & 21.6 & 17.0 & 13.5 & & & $12.2-14.9$ & 2,633 \\
\hline 2003 & 68.4 & 53.9 & 42.1 & 32.2 & 24.7 & 18.5 & 14.6 & 11.5 & 8.9 & & $7.8-10.1$ & 2,317 \\
\hline 2002 & 66.1 & 50.9 & 40.6 & 32.2 & 24.3 & 18.7 & 14.1 & 11.3 & 8.7 & 6.9 & $5.9-8.1$ & 2,090 \\
\hline 2001 & 66.6 & 52.0 & 38.1 & 28.9 & 21.7 & 16.3 & 12.2 & 9.6 & 8.1 & 6.2 & $5.1-7.6$ & 1,557 \\
\hline 2000 & 66.0 & 52.4 & 39.6 & 28.6 & 22.3 & 17.4 & 13.4 & 10.0 & 7.8 & 6.0 & $4.8-7.2$ & 1,497 \\
\hline
\end{tabular}


Table 8.10. Unadjusted survival of incident patients, 1997-2011 cohort for patients of all ages

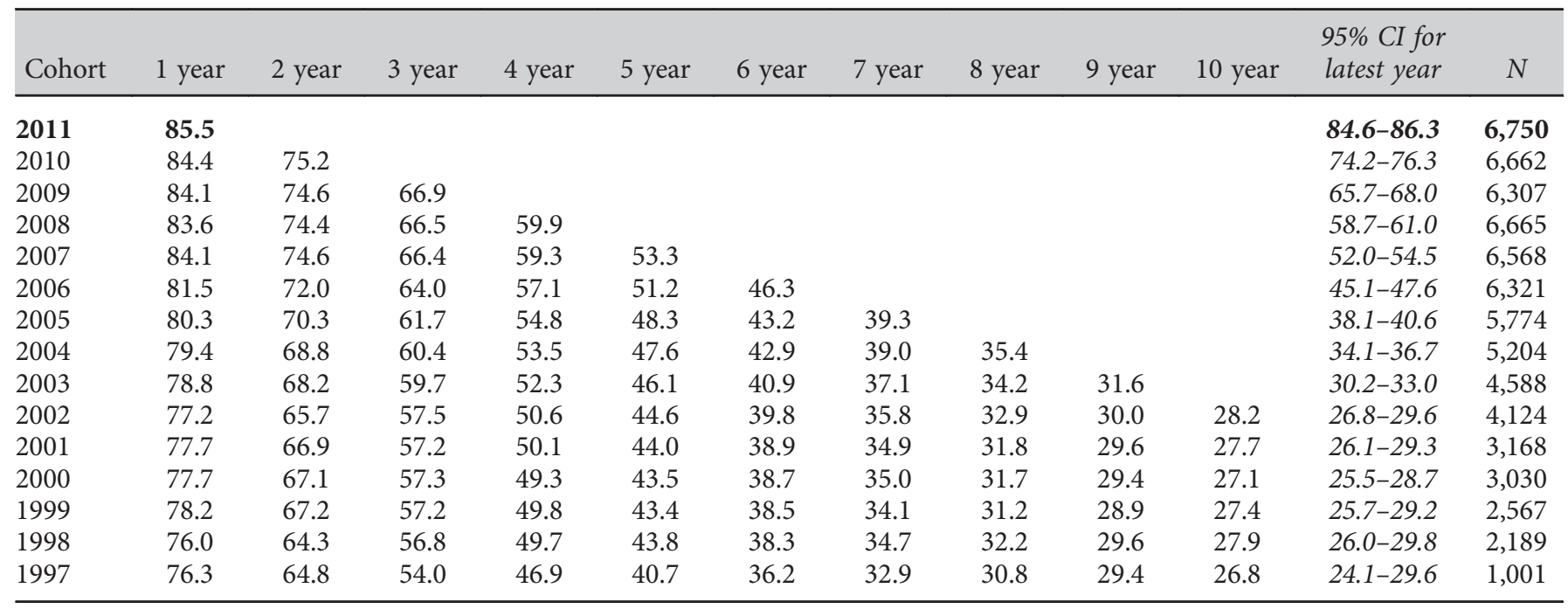

figure 8.4 , it can be seen that $50 \%$ of patients starting RRT aged between $45-54$ survived for over 10 years, $50 \%$ of patients starting RRT aged between 55-64 survived for 5.75 years and $50 \%$ of patients starting RRT aged between 65-74 survived for 3.3 years.

Figure 8.5 shows the survival of incident patients, excluding those who died within the first 90 days and shows that $50 \%$ of patients aged between $55-64$ years survived for 6 years and $50 \%$ of patients aged between 65-74 years survived for 3.6 years.

Censoring at transplantation would make the longer term outcomes of younger patients (who were more likely to have undergone transplantation) appear worse than they actually were. Without censoring, the 10 year

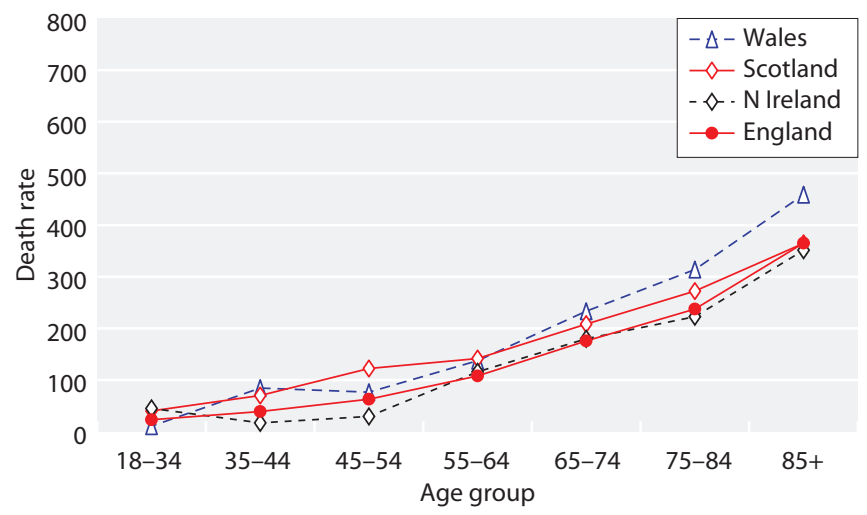

Fig. 8.3. One year after 90 days death rate per 1,000 patient years by UK country and age group for incident patients, 2008-2011 cohort

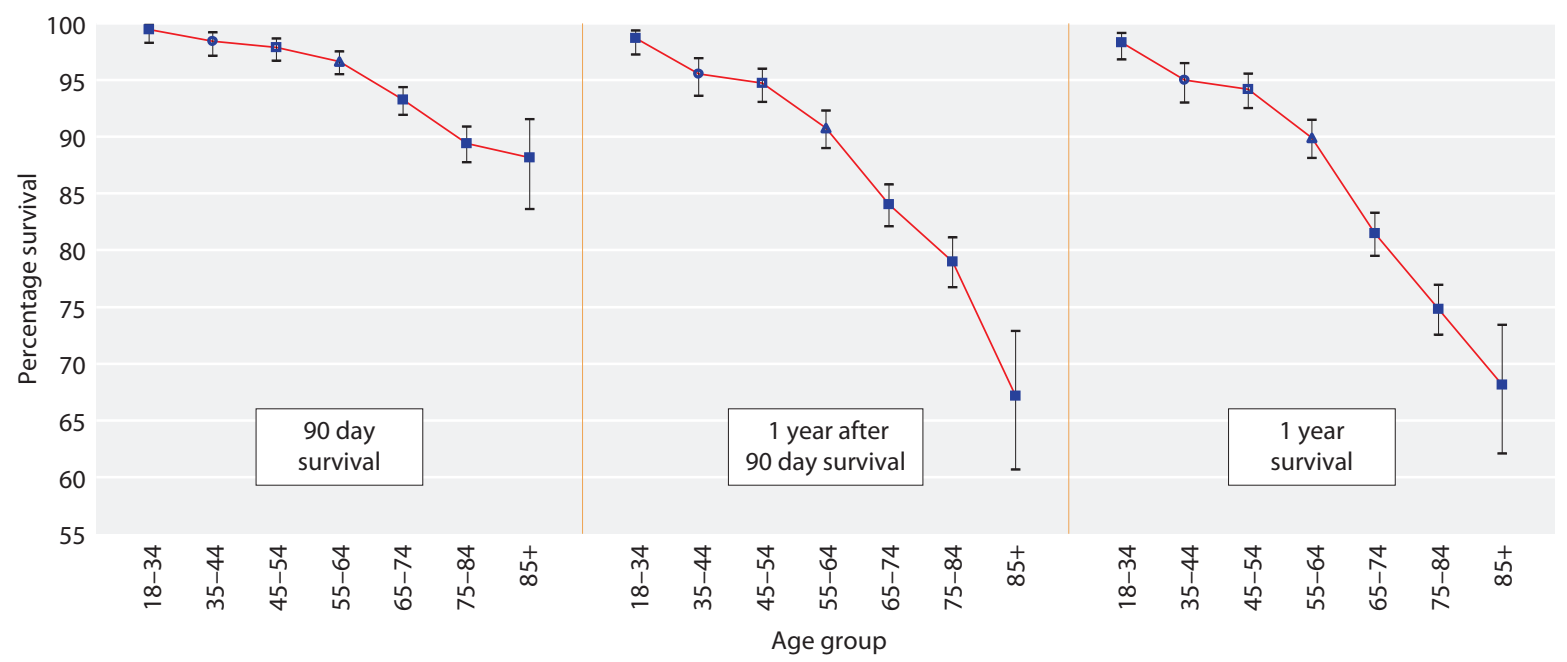

Fig. 8.2. Unadjusted survival of incident patients by age group, 2011 cohort 


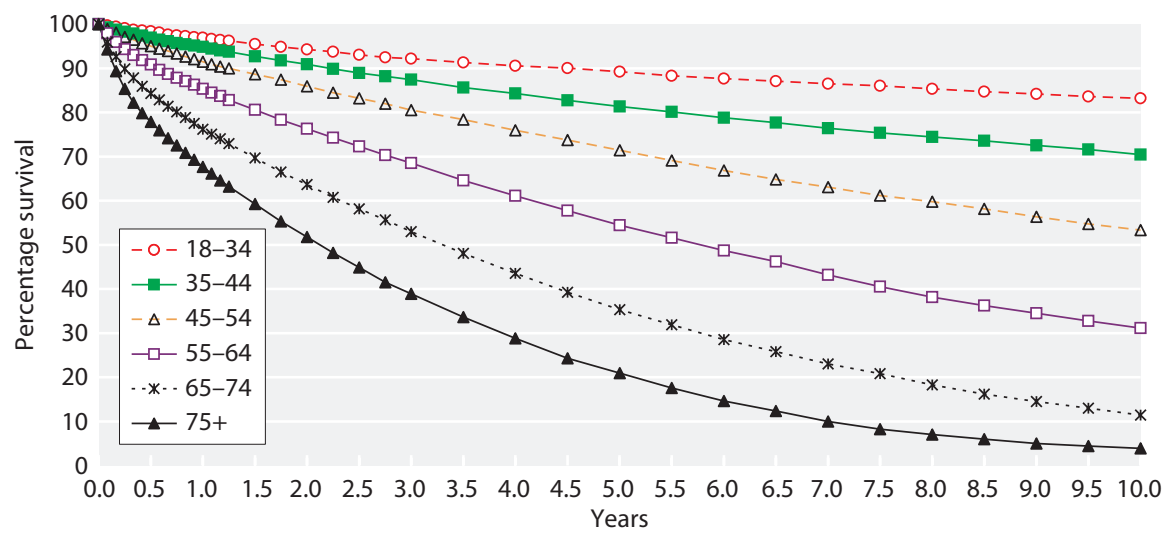

Fig. 8.4. Survival of incident patients (unadjusted), 1997-2011 cohort (from day 0 ), without censoring at transplantation survival for patients aged 18-34 years was $83.6 \%$ (figure 8.4 ), which contrasts with a $57.5 \%$ survival if censoring at the time of transplantation (data not shown). For more detailed information on this effect, refer to the 2008 Report [9].

Age and hazard of death by age in the first 12 months

Figure 8.6 shows the monthly hazard of death from the first day of starting RRT by age group, which falls sharply during the first 4-5 months, particularly for older patients.

A 10 year increase in patient age was associated with a 1.70 times increased risk of death within 90 days and a 1.64 times increased risk of death within 1 year after 90 days (table 8.7).

\section{Changes in survival in the 2000-2011 cohort}

The death rate per 1,000 patient years in the first year of starting RRT from 2000 to 2011 is shown in figure 8.7. There was a declining trend in the overall death rate, although this appears to have levelled off during the last four years. There has been a steeper rate of decline in the older age group (aged 65 years and older).
It is important to note that these death rates are not directly comparable with those produced by the USRDS Registry, as the UK data include the first 90 day period when death rates are higher than subsequent time periods.

The unadjusted survival analyses (tables 8.8, 8.9, 8.10, figures $8.8,8.9$ ) and annual death rates (figure 8.7) show a large improvement in 1 to 10 year survival across the years for both those aged under and those over 65 years. One year survival amongst patients aged less than 65 years at start of RRT has improved from $85.3 \%$ in the 1997 cohort to $93.4 \%$ in the 2011 cohort.

Similarly, for patients aged 65 years and over there has been a $14.2 \%$ absolute improvement in one year survival from the 1997 to 2011 cohorts. As these are observational data it remains difficult to attribute this reduction in risk of death to any specific improvements in care.

\section{Gender}

There were no survival differences between genders in an incident cohort of patients starting RRT from 2000 to 2009 and followed up for a minimum of three years until 2012 (figure 8.10). Gender differences were investigated

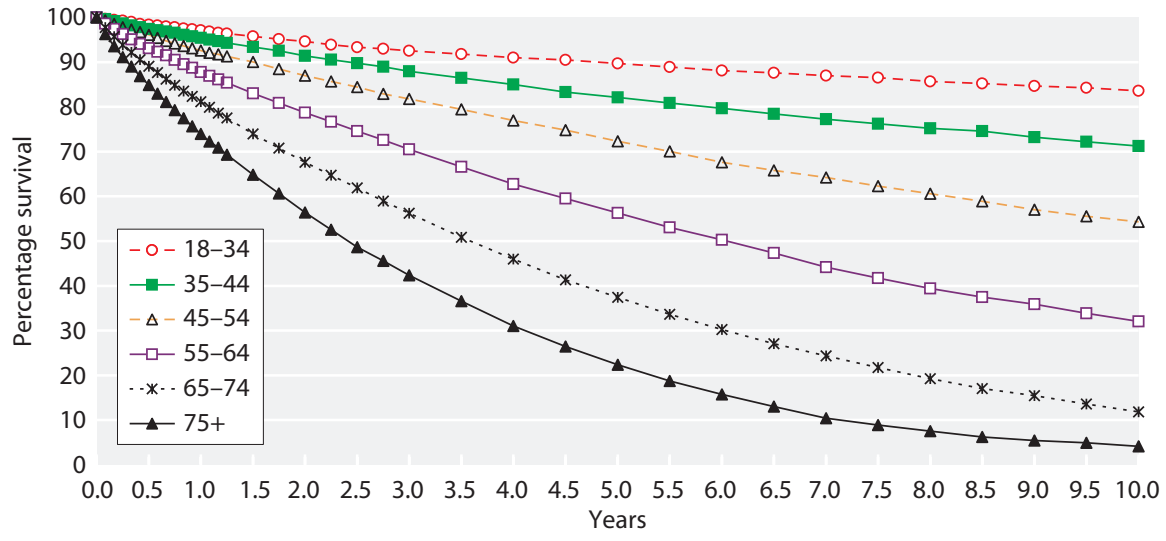

Fig. 8.5. Survival of incident patients (unadjusted), 1997-2011 cohort (from day 90), without censoring at transplantation 


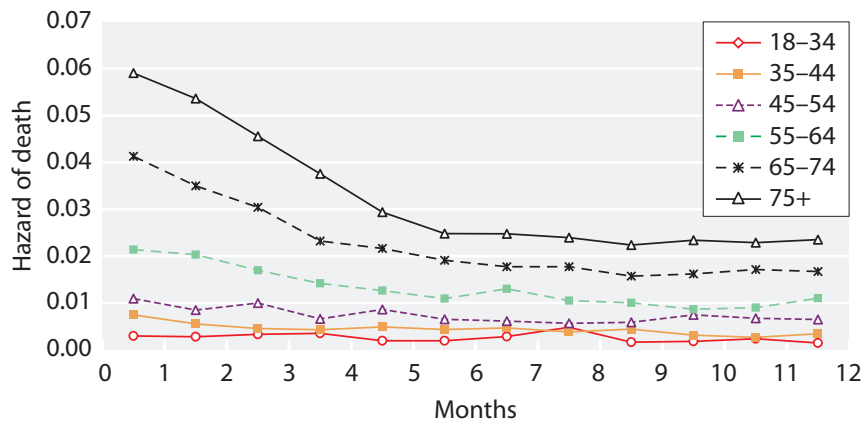

Fig. 8.6. First year monthly hazard of death, by age group 19972011 combined incident cohort

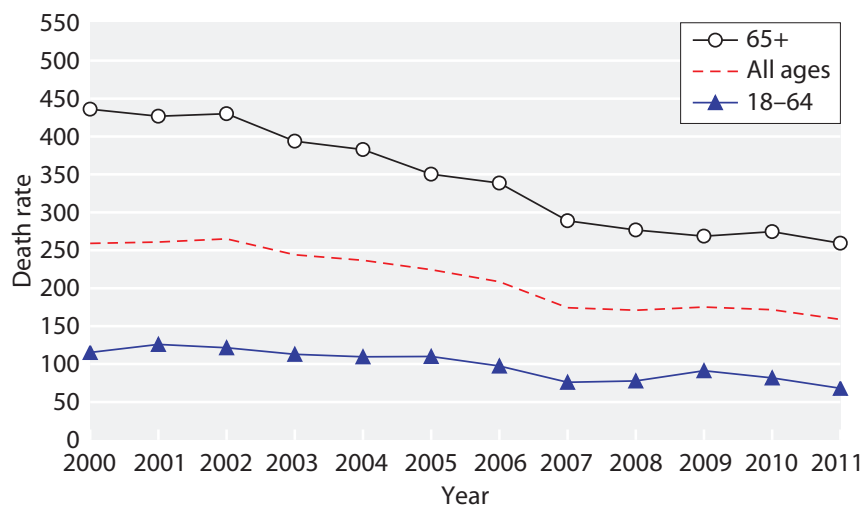

Fig. 8.7. One-year incident death rate per 1,000 patient years by age group, 2000-2011 cohort

in the first 90 days and 1 year after the first 90 days and there was also no evidence of a survival difference (data not shown).

\section{Change in survival on renal replacement therapy by vintage}

Incident RRT patients in the UK continued to show little evidence of a worsening prognosis with time on

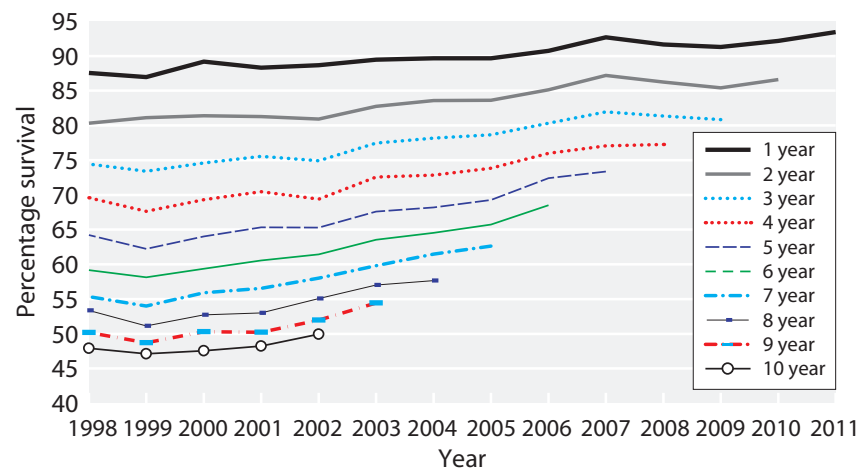

Fig. 8.8. Change in long term survival by year of starting RRT, for incident patients aged 18-64 years

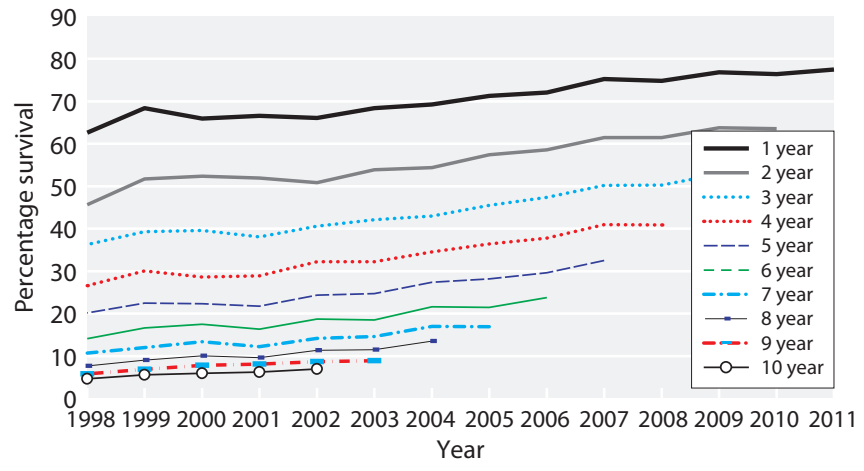

Fig. 8.9. Change in long term survival by year of starting RRT, for incident patients aged 65 years

RRT (vintage) when comparing survival without censoring for transplantation. Figure 8.11 shows the instantaneous hazard of death by age group. The apparent vintage effect when censoring for transplantation (data not shown) is at least in part because these younger and healthier patients are only included in the survival calculation up to the date of transplantation. In the older age groups there were decreasing numbers remaining alive beyond seven years accounting for the increased variability seen. Figures 8.12 and 8.13 show these data for the non-diabetic and diabetic patients respectively. Non-diabetic patients were defined as all incident patients excluding patients with diabetes as the primary renal disease.

Time trend changes in incident patient survival, 2000-2011 cohort

The time trend changes are shown in figure 8.14. The left hand plot, which includes only those centres that have been sending data continuously since 2000 , shows a similar improvement in survival to the plot in which data from all renal centres are analysed.

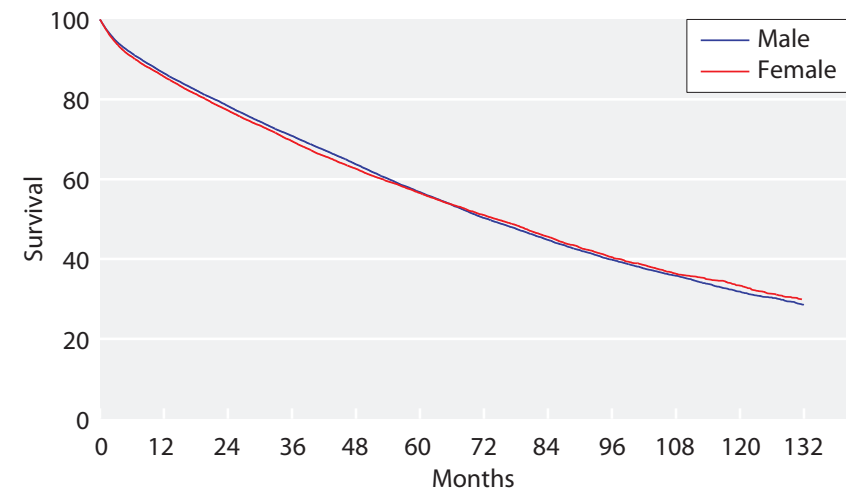

Fig. 8.10. Long term survival of incident patients by gender, 2000-2009 combined cohort, adjusted to age 60

Nephron Clin Pract 2013;125:139-169 

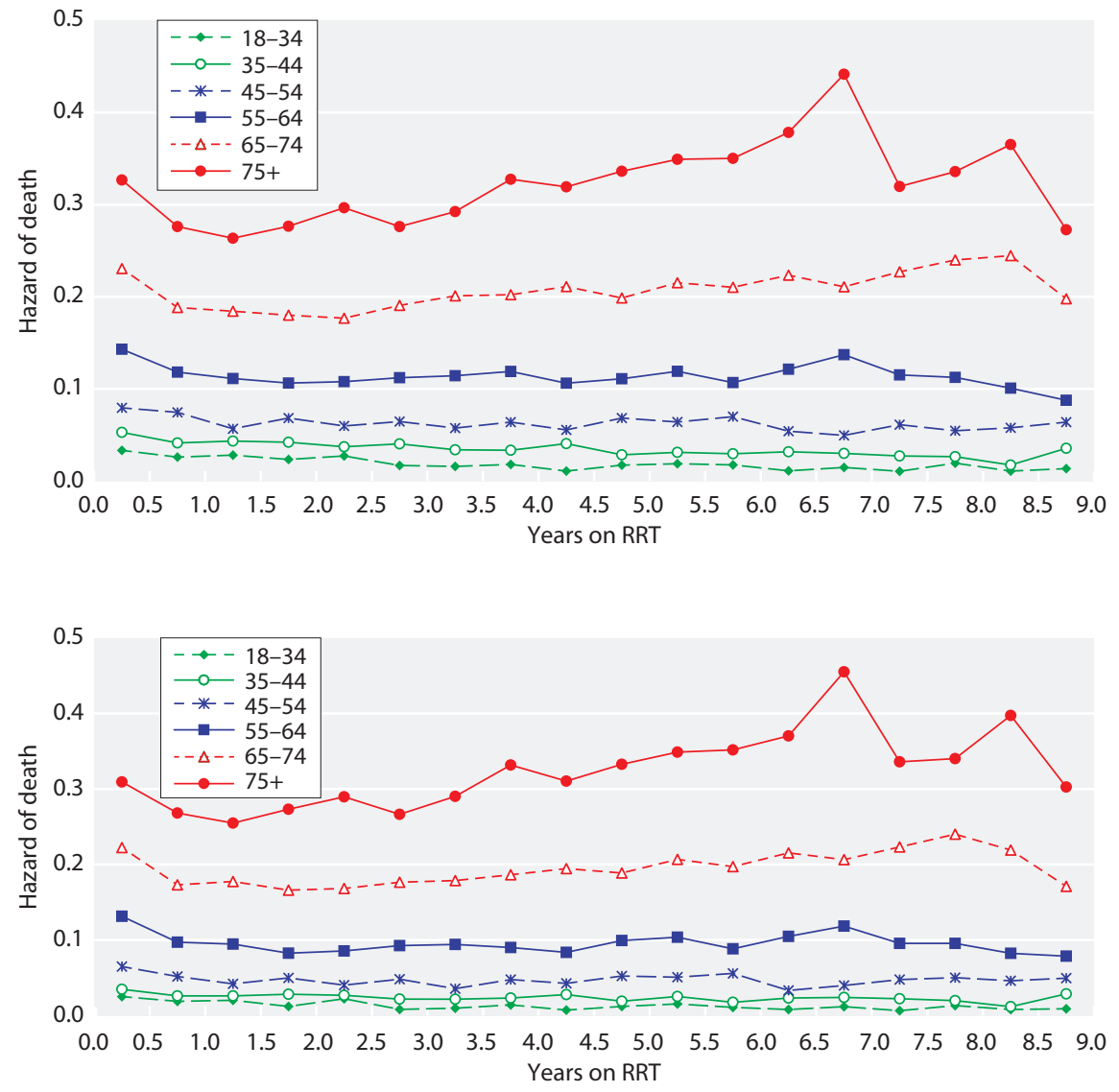

Fig. 8.11. Six monthly hazard of death, by vintage and age group, 1997-2011 incident cohort after day 90 (not censored at transplantation)
Fig. 8.12. Six monthly hazard of death, by vintage and age group, 1997-2011 nondiabetic incident cohort after day 90 (not censored at transplantation)
Analysis of centre variability in 1 year after 90 days survival

The one year after 90 day survival for the 2011 incident cohort is shown in figure 8.15 for each renal centre. The tables for these data and for 90 day survival are given in appendix 1 at the end of this chapter (tables 8.25 and 8.26). The age adjusted individual centre survival for each of the last nine years can also be found in appendix 1 , table 8.27. There was much variability in survival between centres, but these results have to be interpreted cautiously as they were not adjusted for comorbidity, ethnicity or primary renal disease and patient numbers were small in many centres. Survival results for centres with less than 20 incident patients in 2011 (Clwyd, Dumfries \& Galloway, Inverness) are not shown in figure 8.15 , although they were included in the national and UK survival calculations.

In the analysis of 2011 incident cohort survival data, some of the smaller centres had wide confidence intervals (figure 8.15) due to small numbers of patients. This was

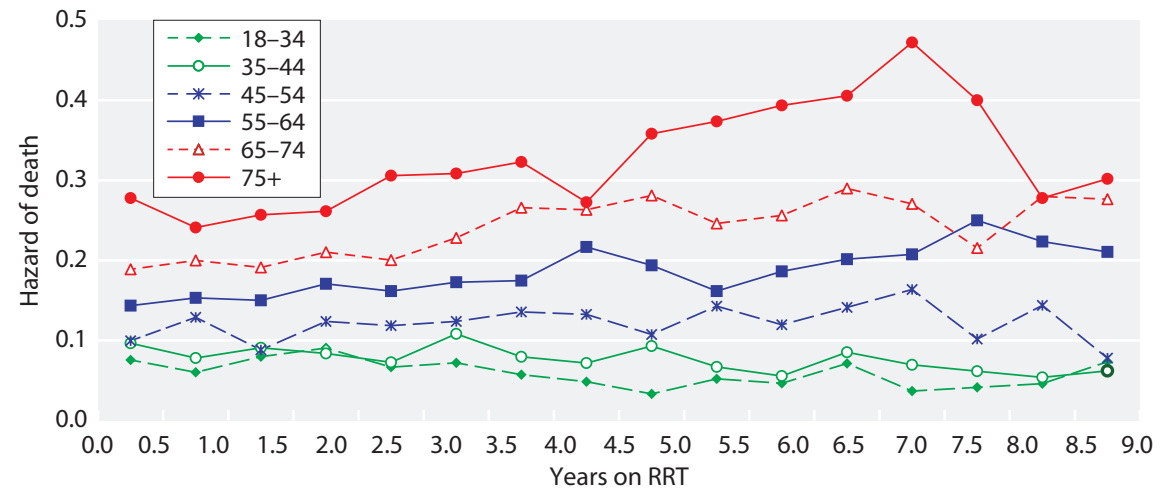

Fig. 8.13. Six monthly hazard of death, by vintage and age group, 1997-2011 diabetic incident cohort after day 90 (not censored at transplantation) 


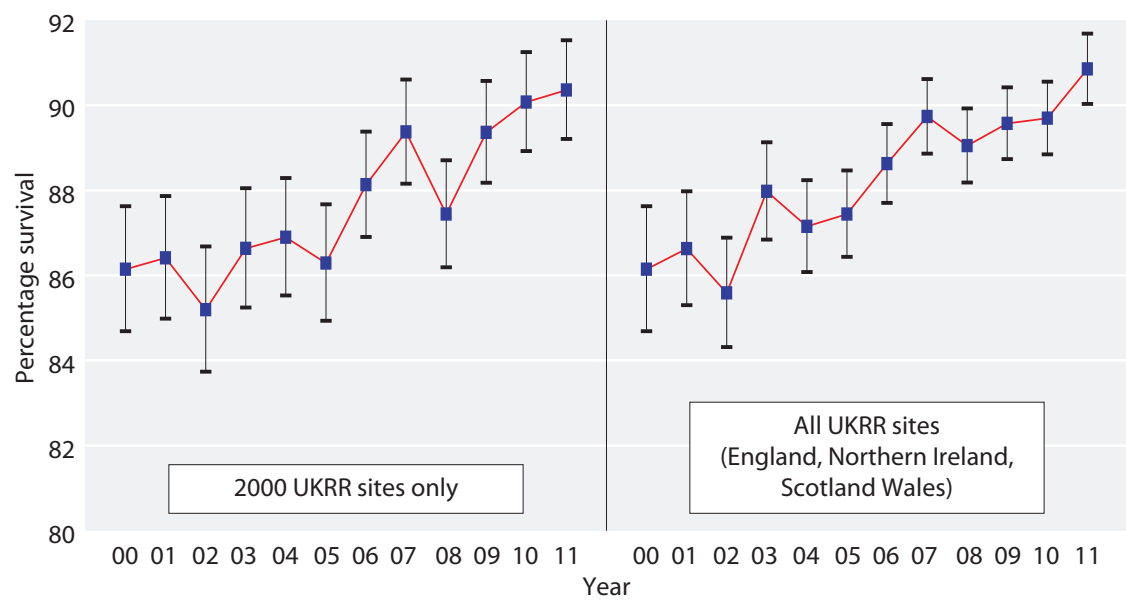

Fig. 8.14. Change in one-year after 90 day survival, 2000-2011 incident cohort (adjusted to age 60)

Showing 95\% confidence intervals

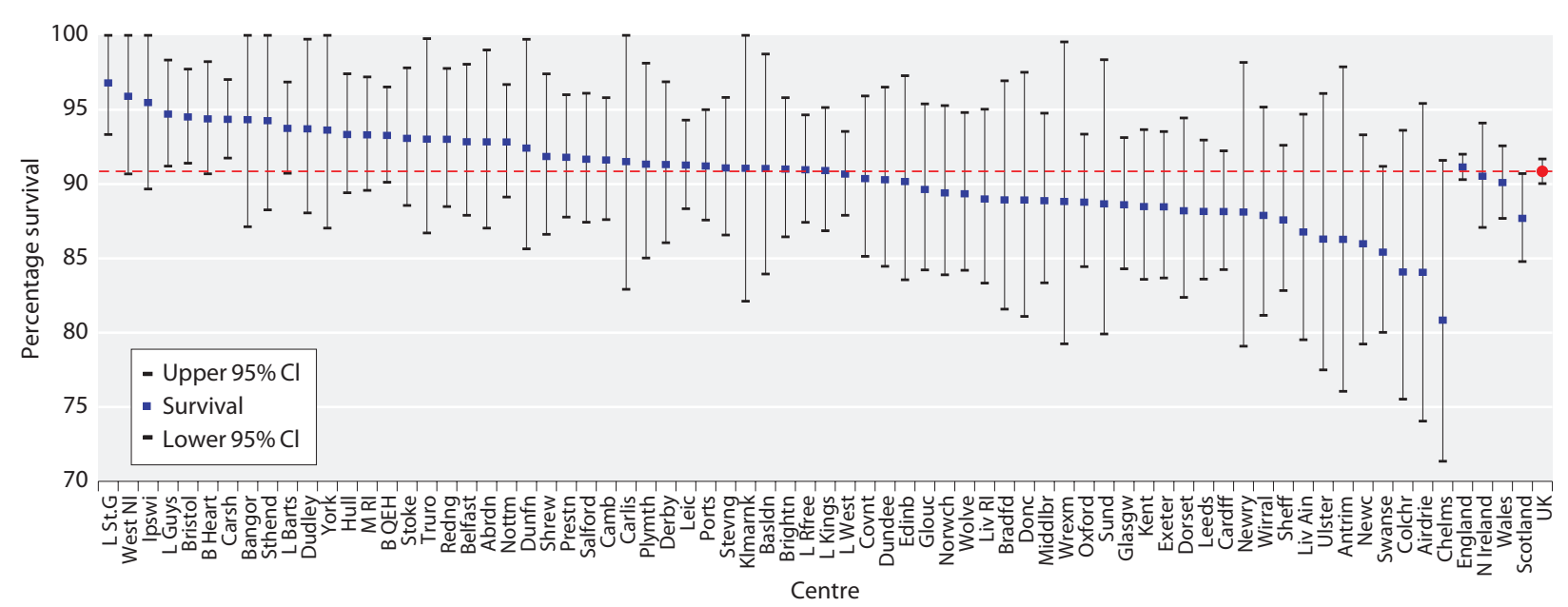

Fig. 8.15. Survival one-year after 90 days, adjusted to age 60,2011 incident cohort

addressed by including a larger cohort across several years, which will also assess sustained performance. Similar to previous years, this is shown as a rolling four year cohort from 2008 to 2011. These data are presented as a funnel plot in figure 8.16 . For any number of patients in the incident cohort (x-axis) one can identify whether any given survival rate (y-axis) falls within, plus or minus 2 standard deviations (SDs) from the national mean (solid lines, 95\% limits) or 3 SDs (dotted lines, 99.9\% limits). Table 8.11 allows centres to be identified on this graph by finding the number of patients treated by the centre and then looking up this number on the $\mathrm{x}$-axis. Two centres (Swansea, Glasgow) had survival below the 95\% lower limit whilst seven centres (Ipswich, London St. George's, Stevenage, London Guys, London Barts, London West, Western Trust Northern Ireland) had survival above the $95 \%$ upper limit. Amongst these, St George's was above the $99 \%$ upper limit having consistently had survival above the $95 \%$ upper limit for the last few years. With 71 centres it would be expected that only three centres would be outside these limits by chance. It is important to acknowledge that these data have not been adjusted for any patient related factor

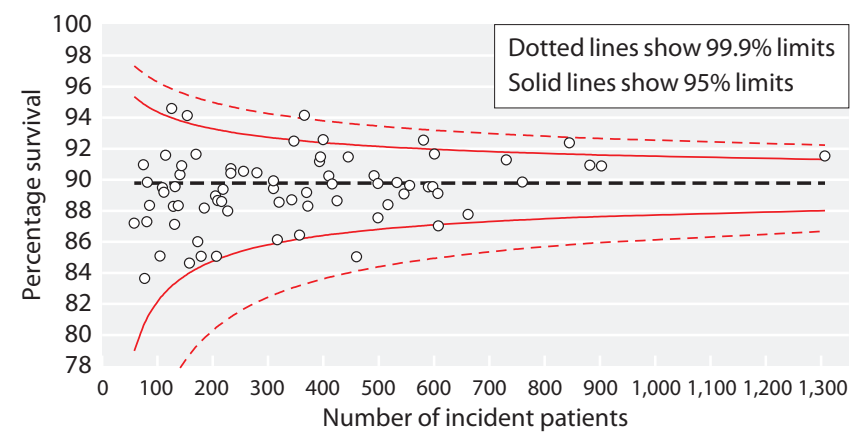

Fig. 8.16. Funnel plot for age adjusted 1 year after 90 days survival, 2008-2011 incident cohort 
Table 8.11. Age adjusted (to age 60) 1 year after 90 day survival, 2008-2011 incident cohort

\begin{tabular}{|c|c|c|}
\hline Centre & $N$ & $\begin{array}{c}1 \text { year after } 90 \text { day } \\
\text { survival } \%\end{array}$ \\
\hline D \& Gall & 58 & 87.2 \\
\hline Clwyd & 75 & 91.0 \\
\hline Ulster & 77 & 83.6 \\
\hline Wrexm & 81 & 87.3 \\
\hline Inverns & 82 & 89.8 \\
\hline Newry & 86 & 88.3 \\
\hline Carlis & 105 & 85.1 \\
\hline Bangor & 109 & 89.5 \\
\hline Sthend & 112 & 89.2 \\
\hline Antrim & 115 & 91.6 \\
\hline West NI & 126 & 94.6 \\
\hline Basldn & 129 & 88.3 \\
\hline Colchr & 131 & 87.1 \\
\hline Donc & 132 & 89.5 \\
\hline Klmarnk & 138 & 88.3 \\
\hline York & 141 & 90.3 \\
\hline Dunfn & 144 & 90.9 \\
\hline Ipswi & 154 & 94.1 \\
\hline Liv Ain & 158 & 84.6 \\
\hline Truro & 170 & 91.6 \\
\hline Airdrie & 173 & 86.0 \\
\hline Dudley & 179 & 85.1 \\
\hline Chelms & 185 & 88.2 \\
\hline Wirral & 205 & 88.9 \\
\hline Sund & 207 & 85.1 \\
\hline Abrdn & 209 & 88.6 \\
\hline Dundee & 216 & 88.6 \\
\hline Shrew & 219 & 89.4 \\
\hline Bradfd & 227 & 88.0 \\
\hline Glouc & 233 & 90.7 \\
\hline Plymth & 233 & 90.4 \\
\hline Belfast & 256 & 90.5 \\
\hline Dorset & 280 & 90.4 \\
\hline Derby & 310 & 89.4 \\
\hline Norwch & 310 & 89.9 \\
\hline Edinb & 317 & 86.1 \\
\hline Wolve & 320 & 88.6 \\
\hline Stoke & 343 & 88.7 \\
\hline
\end{tabular}

\begin{tabular}{|c|c|c|}
\hline Centre & $N$ & $\begin{array}{c}1 \text { year after } 90 \text { day } \\
\text { survival } \%\end{array}$ \\
\hline Redng & 347 & 92.5 \\
\hline Middlbr & 357 & 86.4 \\
\hline L St.G & 366 & 94.1 \\
\hline Hull & 370 & 89.2 \\
\hline Newc & 372 & 88.3 \\
\hline B Heart & 393 & 91.2 \\
\hline Liv RI & 395 & 91.5 \\
\hline Stevng & 400 & 92.6 \\
\hline Covnt & 410 & 90.2 \\
\hline Camb & 416 & 89.7 \\
\hline Brightn & 425 & 88.6 \\
\hline Nottm & 445 & 91.5 \\
\hline Swanse & 460 & 85.0 \\
\hline Exeter & 492 & 90.2 \\
\hline Prestn & 499 & 87.5 \\
\hline Kent & 499 & 89.7 \\
\hline Salford & 517 & 88.4 \\
\hline Leeds & 533 & 89.8 \\
\hline L Kings & 546 & 89.1 \\
\hline M RI & 556 & 89.6 \\
\hline L Guys & 581 & 92.5 \\
\hline Oxford & 590 & 89.5 \\
\hline Ports & 598 & 89.6 \\
\hline Sheff & 601 & 91.7 \\
\hline Bristol & 607 & 89.1 \\
\hline Glasgw & 608 & 87.0 \\
\hline Cardff & 662 & 87.8 \\
\hline L Rfree & 731 & 91.3 \\
\hline Carsh & 760 & 89.8 \\
\hline L Barts & 845 & 92.4 \\
\hline $\mathrm{B}$ QEH & 882 & 90.9 \\
\hline Leic & 903 & 90.9 \\
\hline L West & 1,307 & 91.5 \\
\hline England & 21,226 & 90.1 \\
\hline N Ireland & 660 & 90.4 \\
\hline Scotland & 1,945 & 87.8 \\
\hline Wales & 1,387 & 87.2 \\
\hline UK & 25,218 & 89.8 \\
\hline
\end{tabular}

except age (i.e. not comorbidity, primary renal disease or ethnicity) and have not been censored at transplantation, so the effect of differing centre rates of transplantation was not taken into account. Variation in the proportion of patients with terminal illness receiving RRT between centres could also contribute to variations in survival and provide a possible explanation for lower survival than expected for some centres. In addition, another possible reason why several of the best performing centres are London based could be that they serve large ethnic minority populations which are known to have better survival on dialysis [4].

Analysis of the impact of adjustment for comorbidity on the 1 year after 90 day survival

Although comorbidity returns to the UKRR have remained poor, there was an increase in the number of centres returning more than $85 \%$ of comorbidity data to the UKRR for patients starting RRT in 2011. Using the combined incident cohort from 2007-2011, it was found that 21 centres had returned comorbidity data for more than $85 \%$ of patients and these centres were included in this analysis. Adjustment was first performed to age 60 , then to the average distribution of primary diagnoses for all 21 centres. Further adjustment was 
Table 8.12. The effect of adjustment for age, PRD and comorbidity on survival, 2007-2011 incident cohort, \% survival 1 year after 90 days

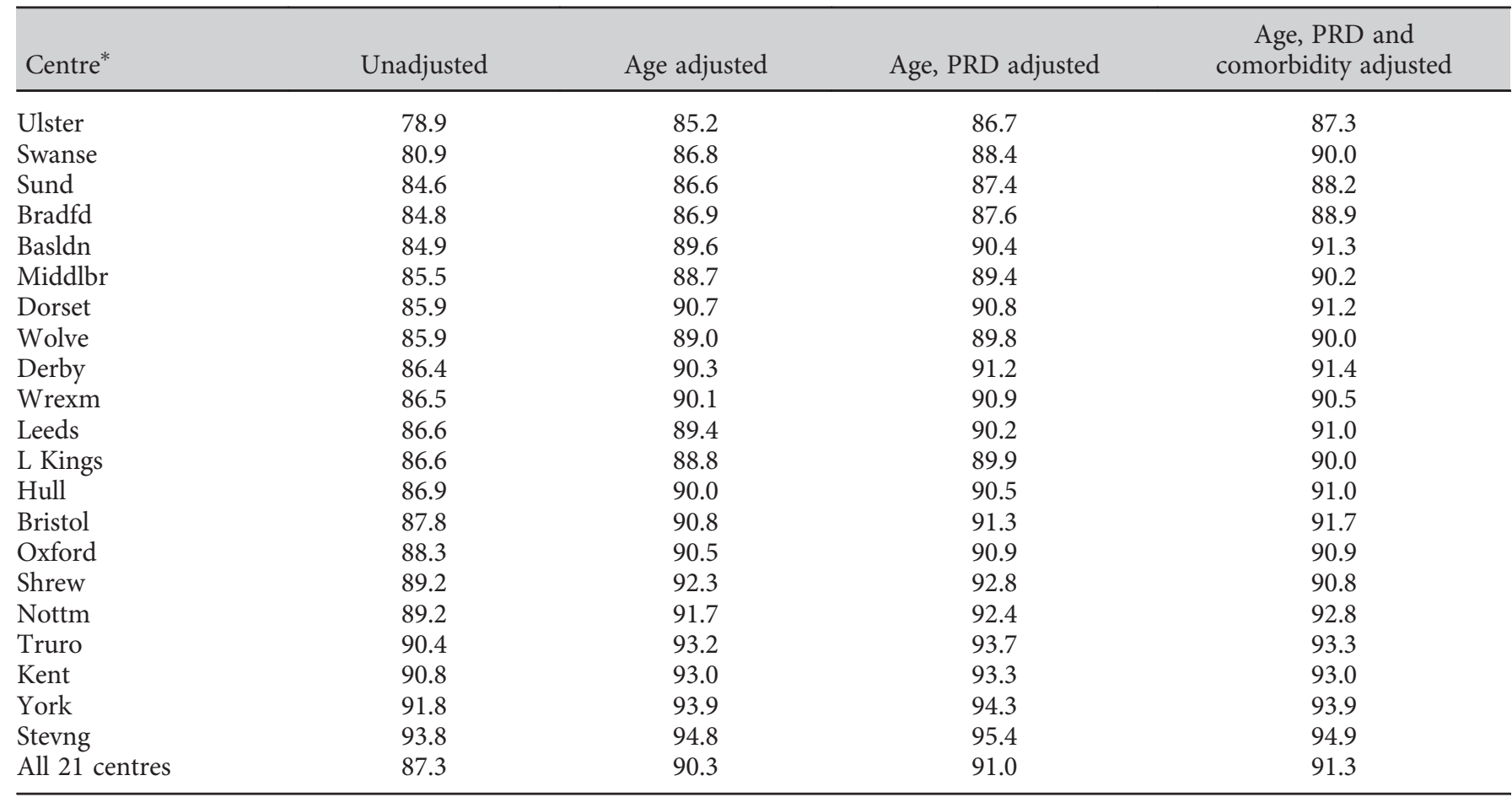

${ }^{*}$ Centre included if $>85 \%$ comorbidity data available

then made to the average distribution of comorbidities present at those centres.

Research has suggested that adjustment for comorbidity explains a modest part of the variance in ERF patient outcomes [10]. At centre level however, the prevalence of comorbidities could vary substantially between patient populations of different centres and it could be expected that adjustment for comorbidity may explain an increased amount of the variance in outcome. It can be seen that adjustment for age has the largest effect, most notably in those centres with the lower unadjusted survival figures. There were only minor differences for most centres after adjustment for primary renal diagnosis. In four centres (Swansea, Bradford, Basildon, Middlesbrough) adjustment for comorbidity had a noticeable effect on adjusted survival (table 8.12, figure 8.17) helping explain the lower survival noted in figure 8.15.

\section{Survival in patients with diabetes}

Although it has previously been shown that diabetic patients have worse long term survival compared to non-diabetic patients [3], non-diabetic patient survival in the older age group (65 years and older) was worse compared to diabetic patients in the same age group during the first 90 days of starting RRT (2011 cohort) (figure 8.18) and in the subsequent year (figure 8.19); this might be due to patient selection.

Long term survival for diabetic and non-diabetic patients was evaluated in a cohort of patients starting RRT from 2000 to 2009 with a minimum of three years follow-up until 2012. These data show large differences in the 18-44 year and 45-64 year age groups between diabetic and non-diabetic patient survival, but there was very little difference in three year survival between diabetics and non-diabetics in the older age group. In the age group $18-44,89 \%$ of non-diabetic patients were alive five years after start of RRT compared to $70 \%$ for diabetic patients. In the age group $45-64,66 \%$ of nondiabetic patients were alive 5 years after start of RRT compared to $49 \%$ for diabetic patients (figure 8.20).

\section{Standard primary renal disease and survival}

It is hard to set survival standards because these should be age, gender, ethnicity and comorbidity adjusted and this is not yet possible from UKRR data. The current 5th edition of the Renal Association Clinical Practice Guidelines [11] does not set any standards for audit of patient survival. 


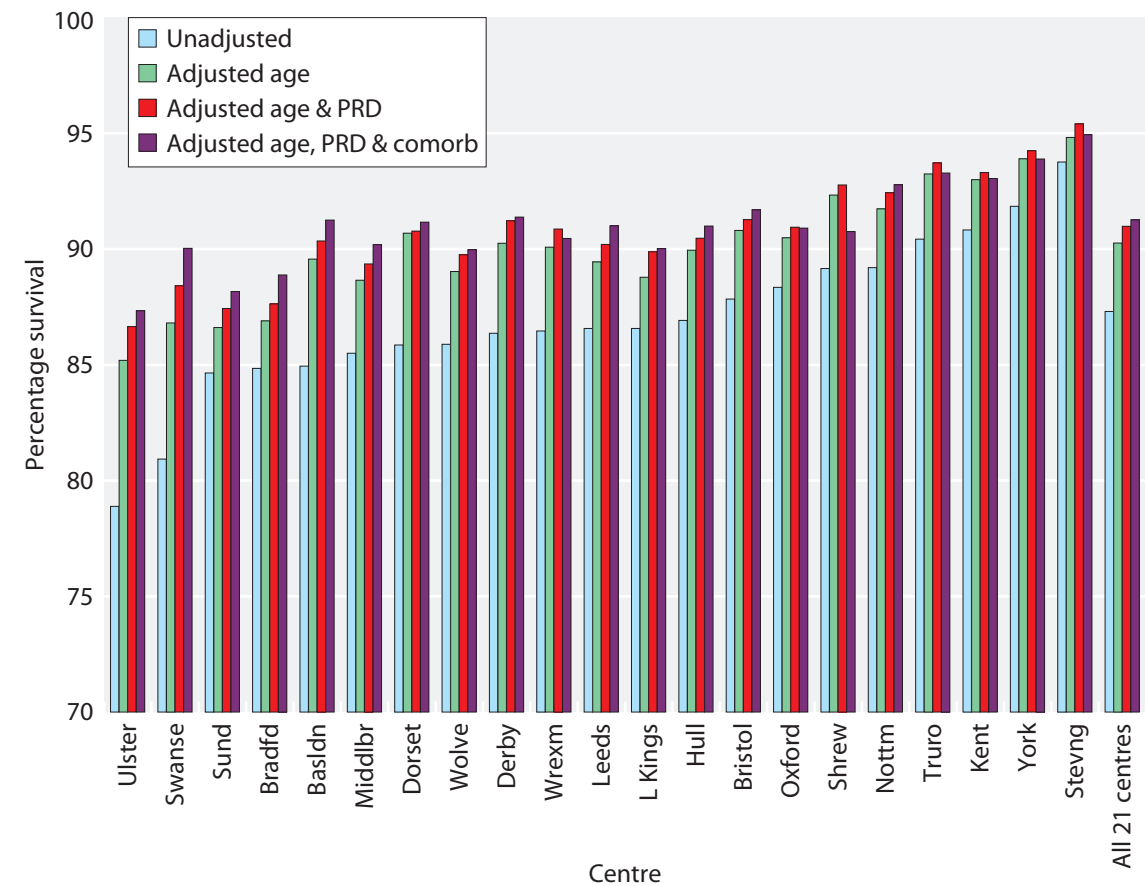

Fig. 8.17. The effect on survival after sequential adjustment for age, $\mathrm{PRD}$ and comorbidity, 2007-2011 incident cohort

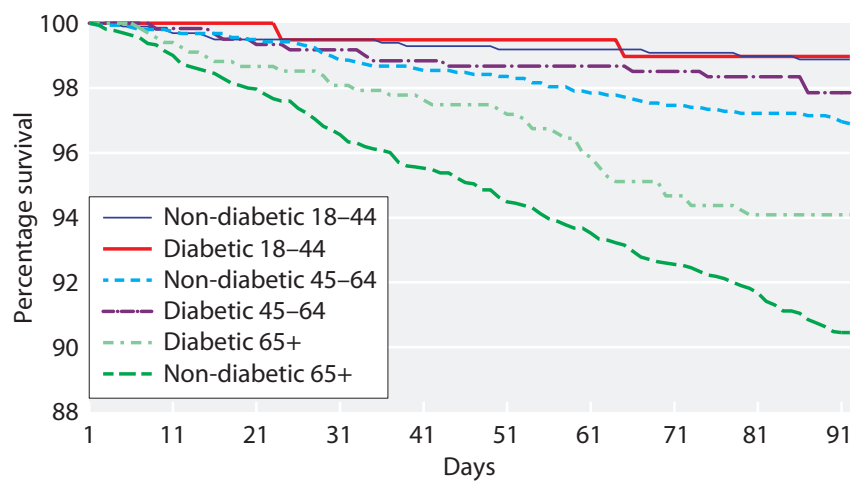

Fig. 8.18. Survival at 90 days for incident diabetic and nondiabetic patients by age group for patients starting RRT, 2011 cohort

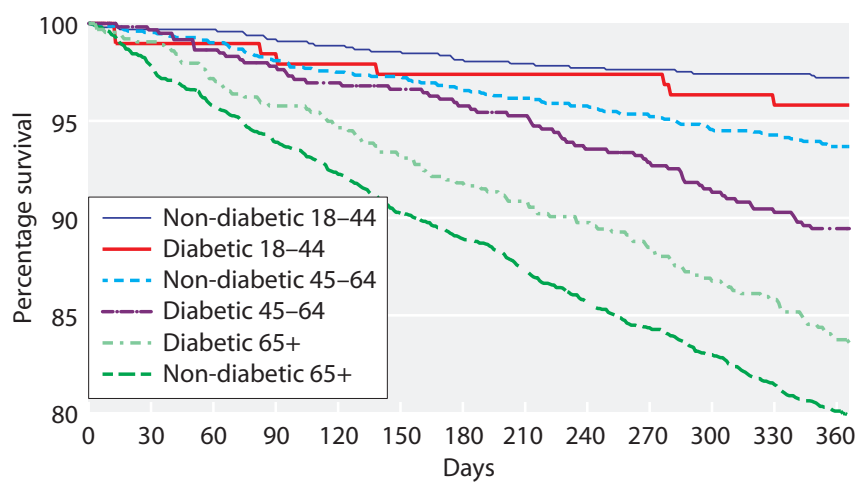

Fig. 8.19. Survival at 1 year after 90 days for incident diabetic and non-diabetic patients by age group for patients starting RRT, 2011 cohort
The 3rd Renal Standards document defined standard primary renal disease using the EDTA-ERA diagnosis codes (including only codes 00-49); this excluded patients with renal disease due to diabetes and other systemic diseases. It is more widespread practice to simply exclude patients with diabetes, so these analyses are also included in this report to allow comparison with reports from other registries. The survival for patients starting RRT in the 2011 cohort in younger age groups (aged 18-54) and followed up for a maximum of one year is shown in table 8.13. For a longer term comparison, the 2002 cohort is also included (table 8.13).

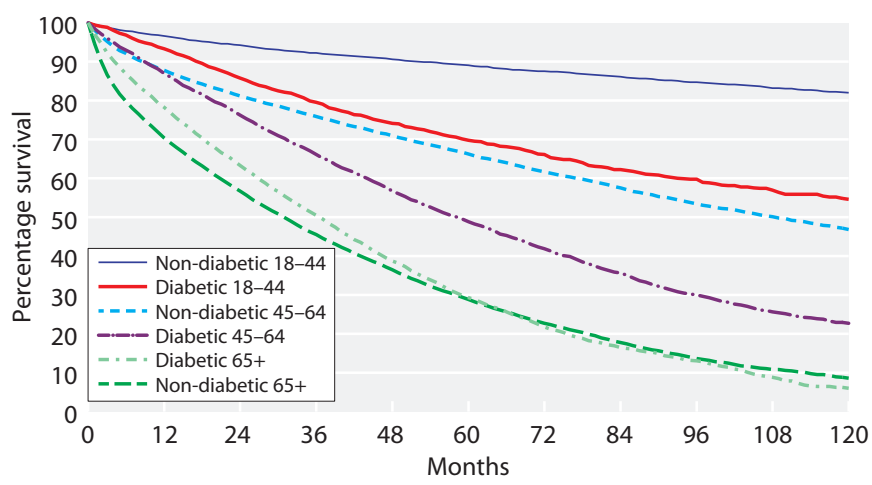

Fig. 8.20. Long term survival for incident diabetic and nondiabetic patients by age group, 2000-2009 cohort, followed up for a minimum of 3 years 
Table 8.13. One-year incident dialysis patient survival (from day 0-365), patients aged 18-54, 2011 and 2002 cohort (excludes patients whose first modality was transplantation)

\begin{tabular}{|c|c|c|c|c|}
\hline \multirow[b]{2}{*}{ First treatment } & \multicolumn{2}{|c|}{2011 cohort } & \multicolumn{2}{|c|}{2002 cohort } \\
\hline & $\begin{array}{l}\text { Standard primary } \\
\text { renal disease }^{\mathrm{a}}\end{array}$ & $\begin{array}{l}\text { All primary renal diseases } \\
\text { except diabetes }{ }^{b}\end{array}$ & $\begin{array}{l}\text { Standard primary } \\
\text { renal disease }^{\mathrm{a}}\end{array}$ & $\begin{array}{l}\text { All primary renal diseases } \\
\text { except diabetes }\end{array}$ \\
\hline All dialysis \% & 97.1 & 95.3 & 95.4 & 93.9 \\
\hline $95 \% C I$ & $95.8-98.0$ & $94.0-96.3$ & $93.7-97.1$ & $92.2-95.5$ \\
\hline HD \% & 96.5 & 94.3 & 93.4 & 91.6 \\
\hline $95 \% C I$ & $94.7-97.7$ & $92.7-95.6$ & $90.7-96.0$ & $89.2-94.0$ \\
\hline PD \% & 98.3 & 97.4 & 98.6 & 97.9 \\
\hline $95 \% C I$ & $96.0-99.3$ & $95.4-98.6$ & $71.1-100$ & $96.3-99.6$ \\
\hline
\end{tabular}

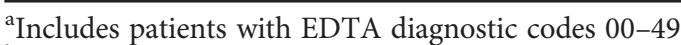

${ }^{\mathrm{b}}$ Excludes patients with diabetes as primary renal disease

\section{Results of prevalent patient survival analyses}

Tables 8.14 and 8.16 show the one year survival on dialysis, after censoring at the time of transplantation. Patients who have been on dialysis for less than 90 days were excluded. One year survival for prevalent dialysis patients remained relatively unchanged at $89.7 \%$ in the 2011 cohort compared to $89.8 \%$ in the 2010 cohort.

Table 8.15 gives the 2011 cohort one year death rate for prevalent dialysis patients in each UK country. The one-year death rate in Wales was significantly higher than in the three other UK countries: the higher median age in Wales together with socio-economic reasons probably explains this.

Figure 8.21 shows the one year survival of dialysis patients who were alive and receiving dialysis on 31 st December 2011, stratified by age group.

\section{One year survival of prevalent dialysis patients by} centre

The age-adjusted one year survival of dialysis patients in each centre is shown in table 8.14 and is illustrated in figures 8.22 and 8.23; the data for those patients aged $<65$ years and those aged 65 years and over are separated. Figure 8.24 shows the age adjusted (adjusted to age 60) data and in figure 8.25 as a funnel plot. The solid lines show the 2 standard deviation limits (95\% limits) and the dotted lines the limits for 3 standard deviations (99.9\% limits). With over 70 centres included, it would be expected by chance that three centres would fall outside the $95 \%$ ( 1 in 20 ) confidence limits. The survival for two centres (Leeds, Cardiff) was below the 95\% confidence limits and for two centres (London West, Birmingham QEH) was above the $95 \%$ confidence limits. The funnel plot analysis shows an improvement in prevalent dialysis patient survival compared to the 2010 cohort when three centres were outliers below the $95 \%$ lower limits compared to two centres in this most recent analysis. The number of centres that were outliers above the 95\% upper limit decreased from five in the 2010 cohort to two in this most recent analysis.

The effect of censoring at transplantation on survival was investigated in the 2011 prevalent dialysis cohort. Results show that this had a minimal effect on prevalent dialysis patient 1 year survival and outlier status (data not shown). Table 8.14 allows centres in figure 8.25 to be identified by finding the number of patients treated by the centre and the corresponding survival and then looking this up on the axes of the funnel plot.

The one year death rate in prevalent dialysis patients in the 2011 cohort by age group

The death rates for prevalent patients on dialysis by age group are shown in figure 8.26. The younger patients included in this analysis are a selected higher risk group, as the similar aged transplanted patients have been excluded. The increase in the death rate was not linear with age; with a 10 year increase in age in the younger patients, the death rate increased by about 10 deaths per 1,000 patient years compared with an increase of 160 deaths per 1,000 patient years in the older age groups. The apparent differences between the countries were not statistically significant except for Wales where the death rate was significantly higher compared to England.

One year survival of prevalent dialysis patients by UK country, 2000 to 2011 cohort

One year survival for prevalent patients seemed to be improving in most of the UK countries (figure 8.27). In Northern Ireland and Wales numbers were much 
Table 8.14. One year survival of prevalent dialysis patients in each centre (adjusted to age 60), 2011 cohort

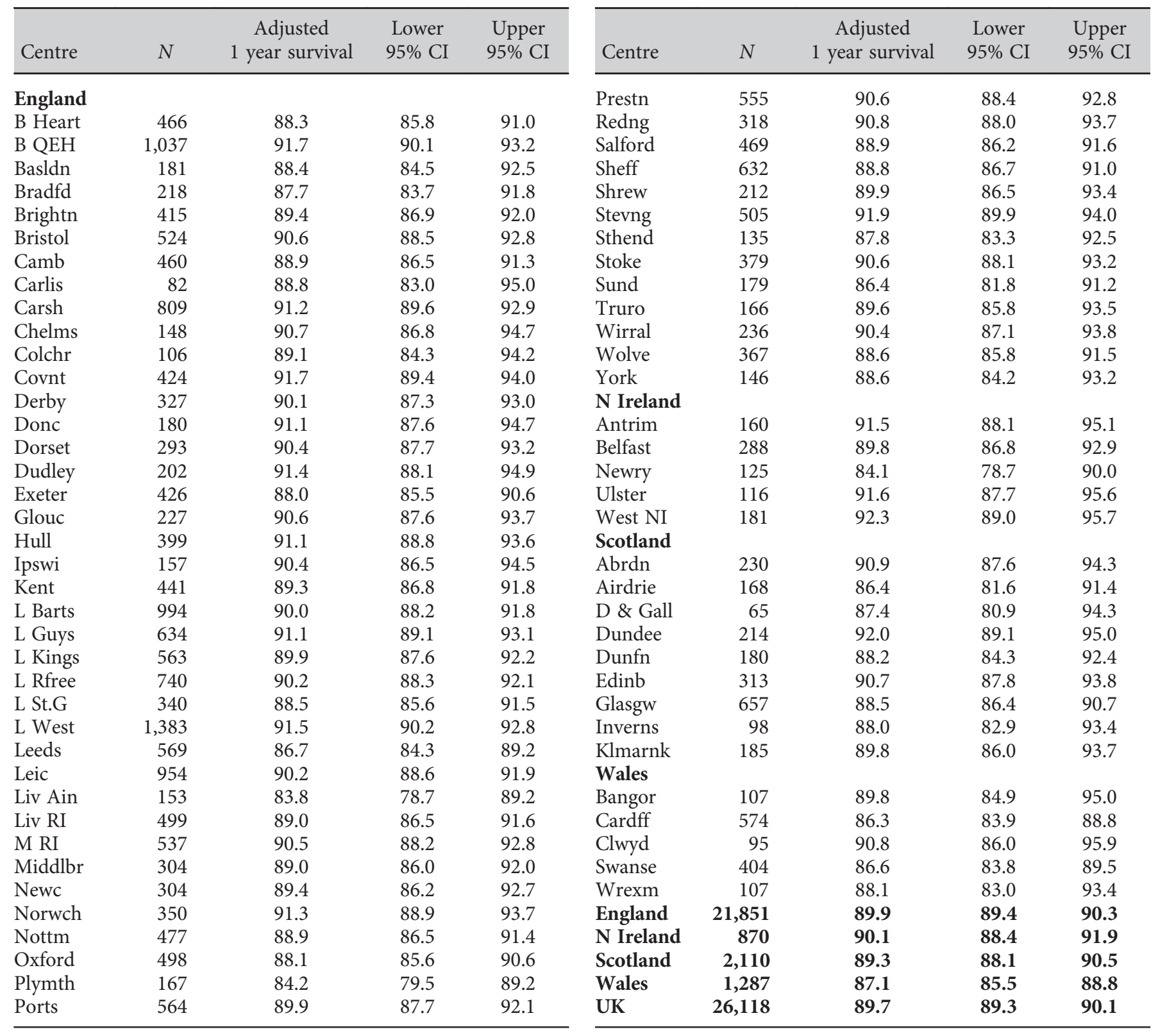

smaller, the death rate was therefore more variable with very wide confidence intervals and it is difficult to

Table 8.15. One-year death rate per 1,000 prevalent dialysis patient years in the 2011 cohort and median age of prevalent patients by country

\begin{tabular}{lcccc}
\hline & England & N Ireland & Scotland & Wales \\
\hline Death rate & 149 & 155 & 156 & 207 \\
95\% CI & $144-155$ & $129-185$ & $139-175$ & $181-235$ \\
Median age & 66.1 & 68.6 & 66.1 & 68.1 \\
\hline
\end{tabular}

draw conclusions on trends in these countries. The change in prevalent survival by centre over the cohort years 2002 to 2011 is shown in this chapter, appendix 1 , table 8.28.

One year survival of prevalent dialysis patients with a primary diagnosis of diabetes, 2002 to 2011 cohort years

The age-adjusted survival for patients with diabetic renal disease in the UK has increased slightly in the 2011 cohort year to $84.9 \%$ (table 8.17). 
Table 8.16. One-year survival of prevalent RRT patients in the UK (unadjusted unless indicated otherwise)

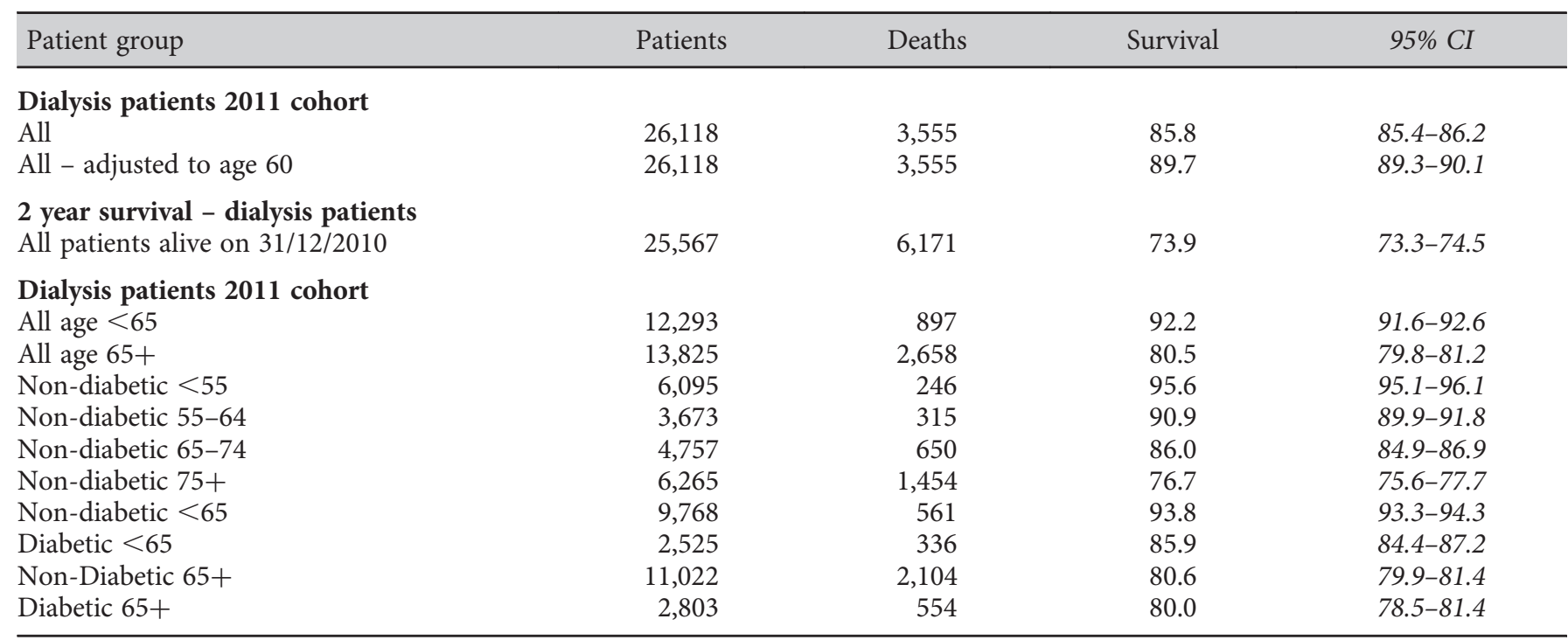

Cohorts of patients alive on $31 / 12 / 2011$ unless indicated otherwise

\section{Death rate on RRT compared with the UK general population}

The death rate compared to the general population is shown in table 8.18. Figure 8.28 shows that the relative risk of death on RRT decreased with age from 16.6 times that of the general population at age 35-39 years to 2.7 times the general population at age 85 and over. Figure 8.28 also shows that the relative risk of death has decreased substantially for the younger age groups ( $<50$ years of age) compared to the relative risk of death in the 1998-2001 cohort. The relative risk of death was unchanged at 6.1, in the 2011 cohort as it

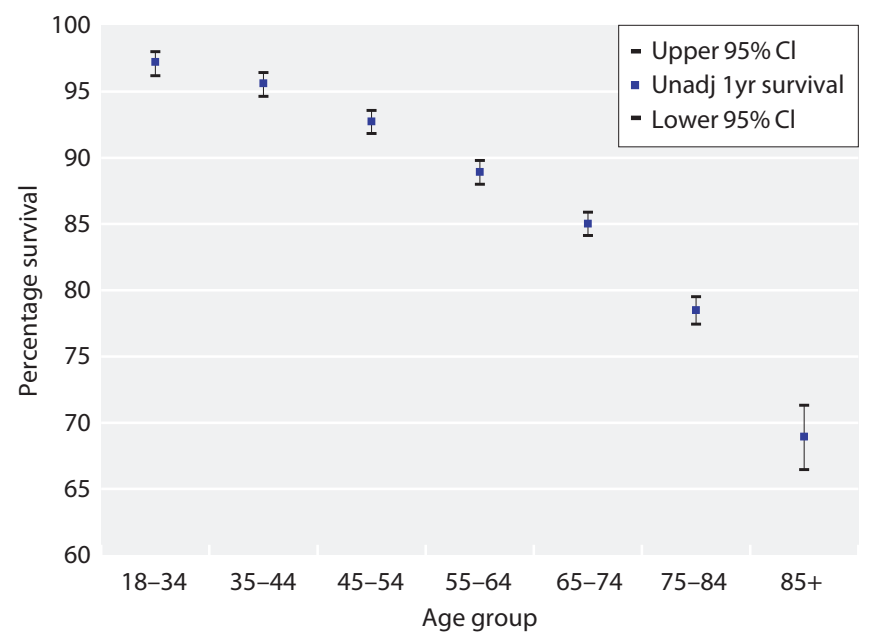

Fig. 8.21. One year survival of prevalent dialysis patients by age group, 2011 cohort was in the 2010 cohort. With the reduction in rates of death on RRT over the last 10 years, the relative risk of death is falling (7.7 in 1998-2001 cohort, 6.1 in 2011 cohort).

\section{Results of analyses on causes of death}

\section{Data completeness}

Having increased significantly in recent years, data completeness for cause of death data in the UK showed only a marginal rise of $0.2 \%$ (table 8.19 ) with both Northern Ireland and Scotland recording more than $85 \%$ of cause of death data. Northern Ireland centres overall had the highest rate of data return for cause of death $(92.3 \%)$ and their cause of death completeness improved by about 3\% compared with the previous year. Patterns of cause of death must be cautiously interpreted, as there are significant differences between the cause of death for centres with a high proportion of non-returns when compared to centres with good returns (70\%). Some centres consistently achieve a very high rate of data return for cause of death because a process is in place to ensure that these data were entered. Several centres have shown significant improvement in data returns, but unfortunately some centres that were reporting these data in previous years have stopped reporting cause of death data. There is still much variability between the centres regarding the completeness of 


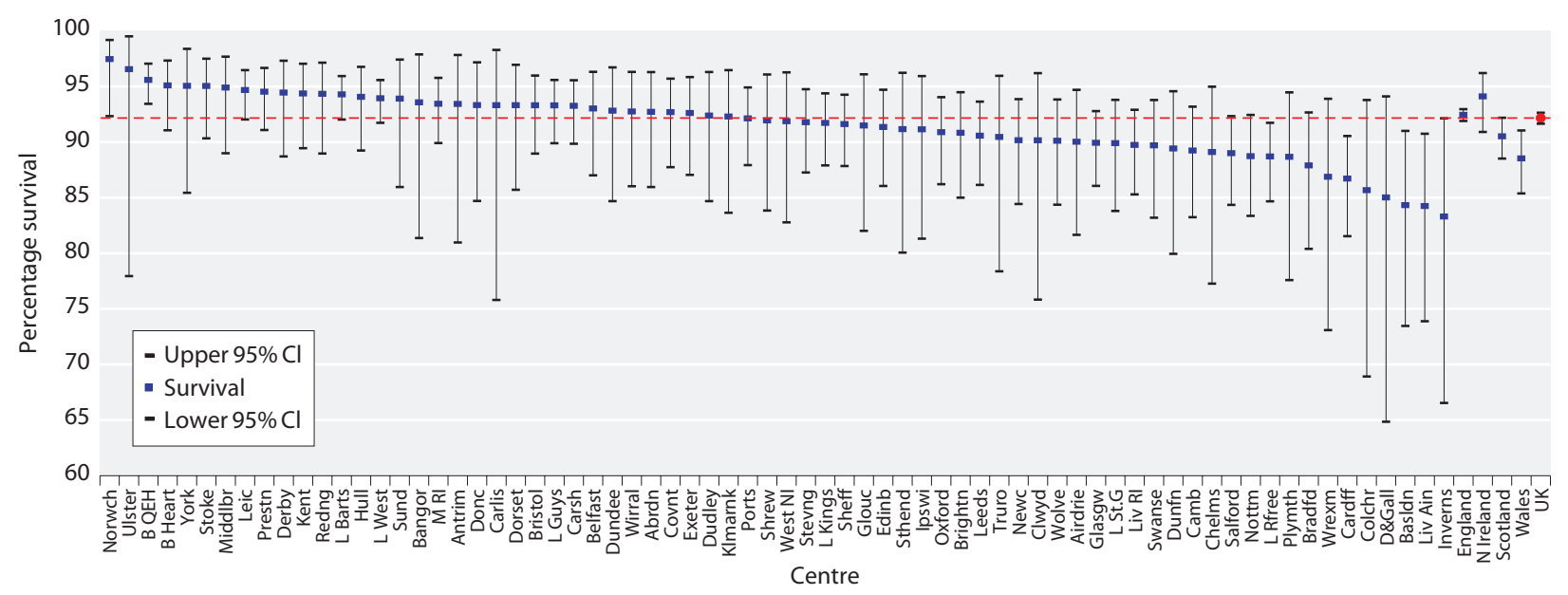

Fig. 8.22. One year survival of prevalent dialysis patients aged under 65 by centre, 2011 cohort

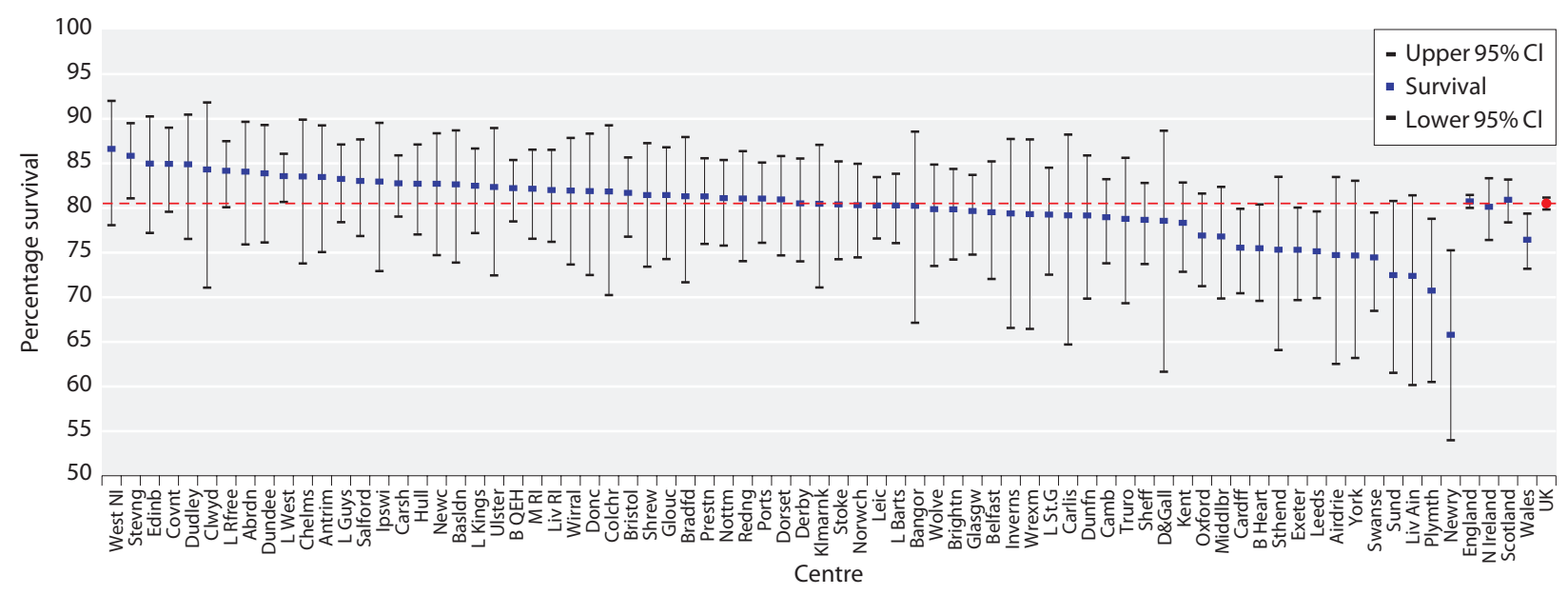

Fig. 8.23. One year survival of prevalent dialysis patients aged 65 years and over by centre, 2011 cohort

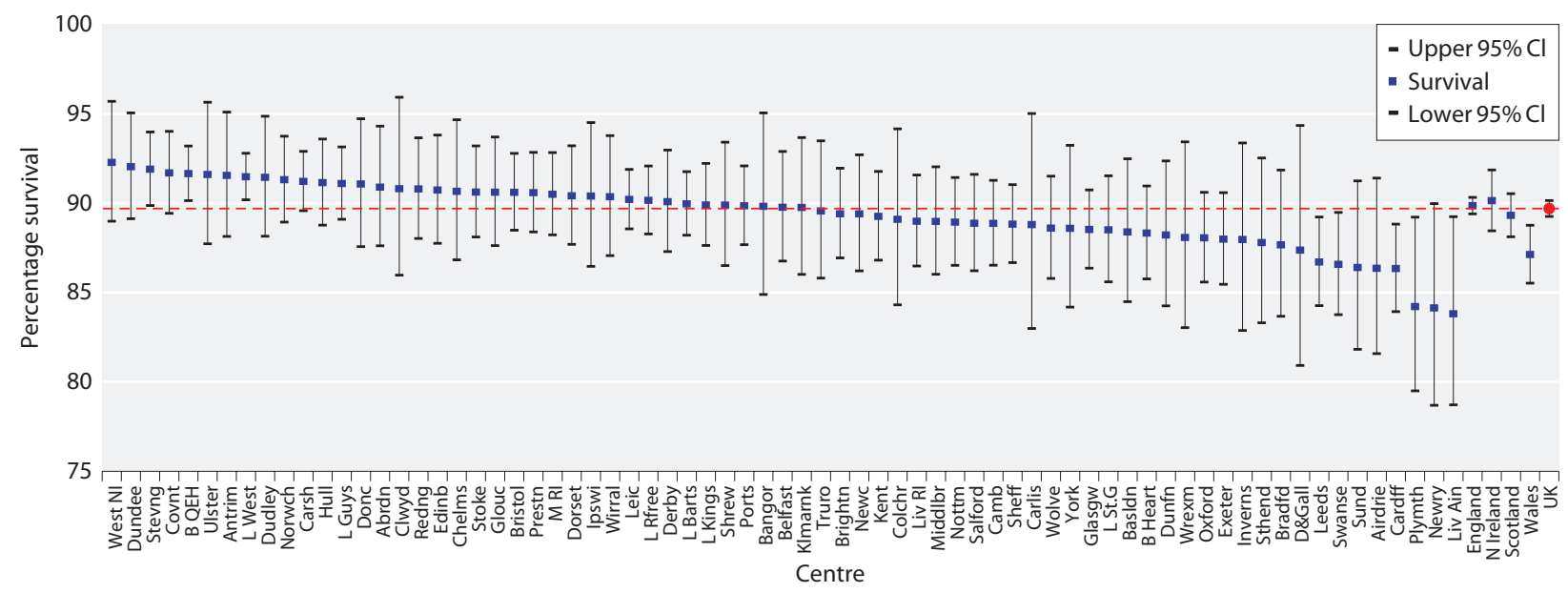

Fig. 8.24. One year survival of prevalent dialysis patients by centre adjusted to age 60,2011 cohort 


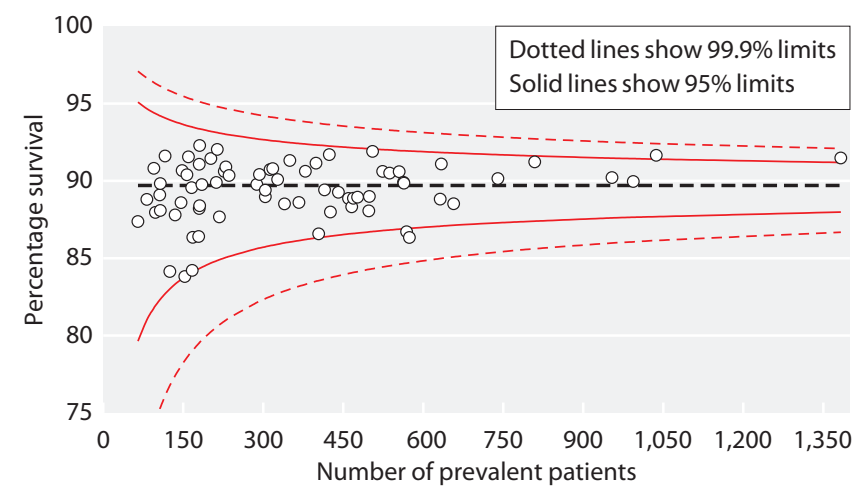

Fig. 8.25. One year survival funnel plot of prevalent dialysis patients by centre adjusted to age 60, 2011 cohort

cause of death with some centres returning no data and other centres having $100 \%$ completeness (table 8.19).

Causes of death in incident RRT patients

Causes of death within the first 90 days

See table 8.20.

Cause of death within one year after 90 days

Treatment withdrawal as a cause of death (tables 8.20, 8.21) in incident patients in the first 90 days and one year after 90 days was more common in older (aged $65+)$ patients and malignancy more common in younger patients ( $<65$ years old). Infection within the first 90 days as the cause of death was more common in older patients. Cardiac disease remained the leading cause of death both in the first 90 days and one year after 90 days.

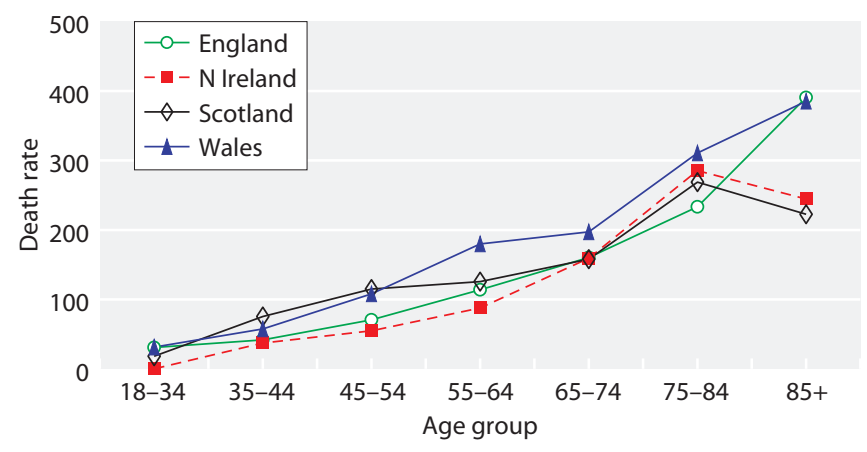

Fig. 8.26. One year death rate per 1,000 patient years by UK country and age group for prevalent dialysis patients, 2011 cohort

Cause of death in prevalent RRT patients in the 2011 cohort

Table 8.22, figures 8.29 and 8.30 show the cause of death for both prevalent dialysis and transplant patients in the 2011 cohort. These data are neither age adjusted nor adjusted for differences in the comorbidity between the two groups. Cardiac disease as a cause of death was less common in transplanted patients as these were a pre-selected low risk group of patients. Malignancy and infection were both responsible for a greater percentage of deaths in prevalent transplanted patients, with treatment withdrawal a common cause of death in the prevalent dialysis population.

Table 8.23 shows that malignancy and infection were slightly more common in younger ( $<65$ years) prevalent transplanted patients as the cause of death than in older (65 years old) transplanted patients.

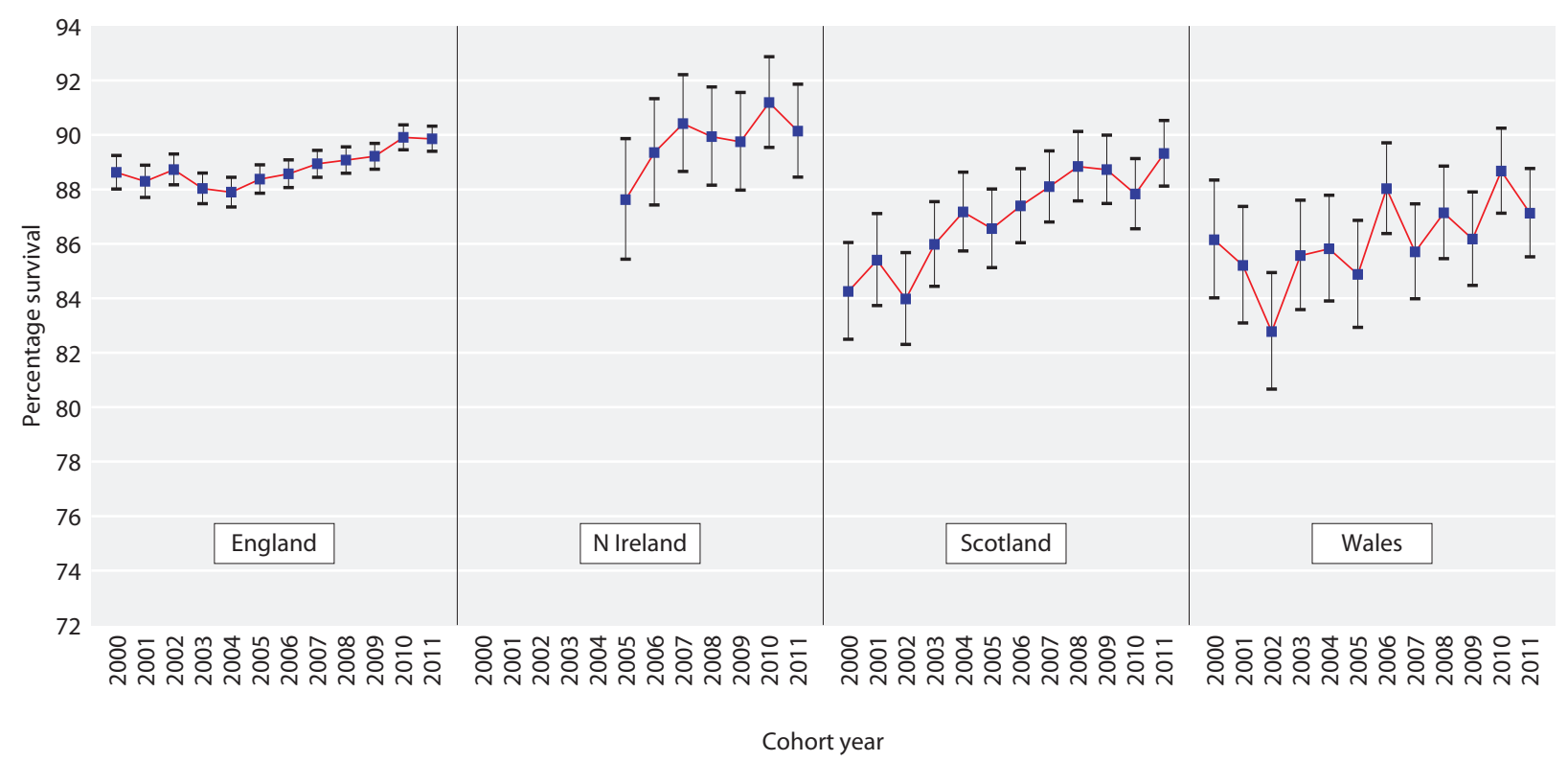

Fig. 8.27. Serial 1 year survival for prevalent dialysis patients by UK country, 2000 to 2011 cohort years, adjusted to age 60 
Table 8.17. Serial 1 year survival of prevalent dialysis patients with a primary diagnosis of diabetes, 2002-2011 cohort years

\begin{tabular}{lcccccccccc}
\hline Year & 2002 & 2003 & 2004 & 2005 & 2006 & 2007 & 2008 & 2009 & 2010 & 2011 \\
\hline 1 year survival \% & 81.6 & 81.7 & 82.8 & 82.4 & 84.7 & 83.5 & 83.9 & 83.3 & 84.8 & 84.9 \\
\hline
\end{tabular}

Table 8.18. Death rate by age group for all prevalent RRT patients, 2011 cohort, compared with the general population and with previous analyses in the 1998-2001 cohort

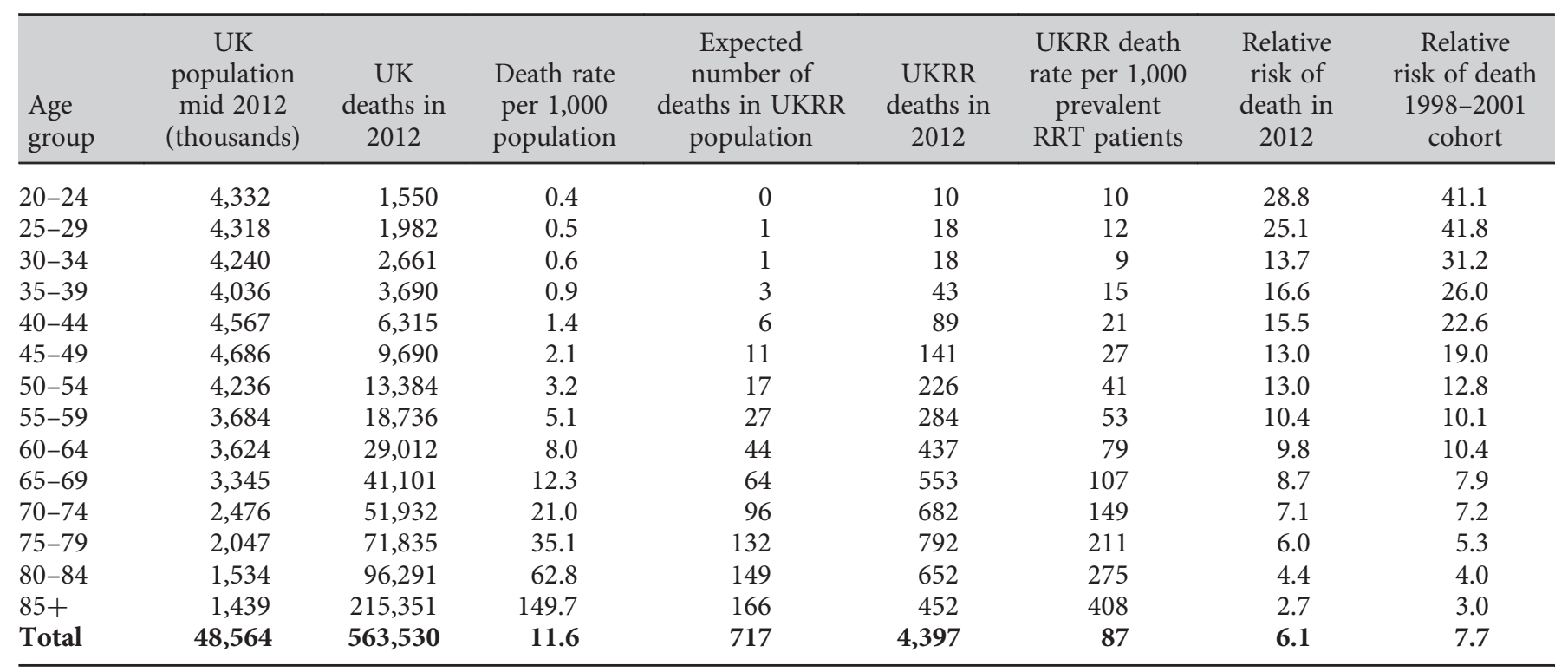

Table 8.24 shows the cause of death for prevalent dialysis patients in the 2011 cohort. Prevalent dialysis patients aged 65 years and over were substantially more likely to withdraw from treatment than younger patients and cardiac disease was much more common as a cause of death in younger ( $<65$ years) dialysis patients. Figure 8.31 shows cause of death for prevalent patients in the 2000 to 2011 cohort. Over time, cardiac disease as cause of death has decreased markedly and there has been a gradual decline in cerebrovascular disease as a cause of death. The proportion of patients coded with 'other' cause of death has increased, as has treatment withdrawal (19\% in 2011 cohort). Infection as cause of death remained at a similar level to the 2000 cohort (figure 8.31).

\section{Median life expectancy on RRT}

The statistical methodology for this analysis is described in the methodology section at the start of this

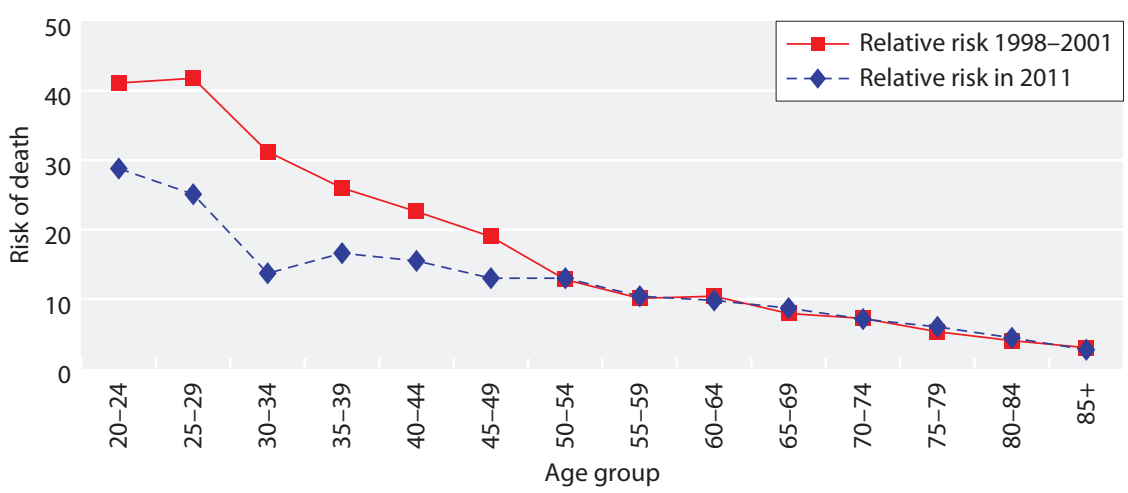

Fig. 8.28. Relative risk of death in all prevalent RRT patients in the 2011 cohort compared with the UK general population 
Table 8.19. Percentage completeness of EDTA cause of death for prevalent patients by centre and year

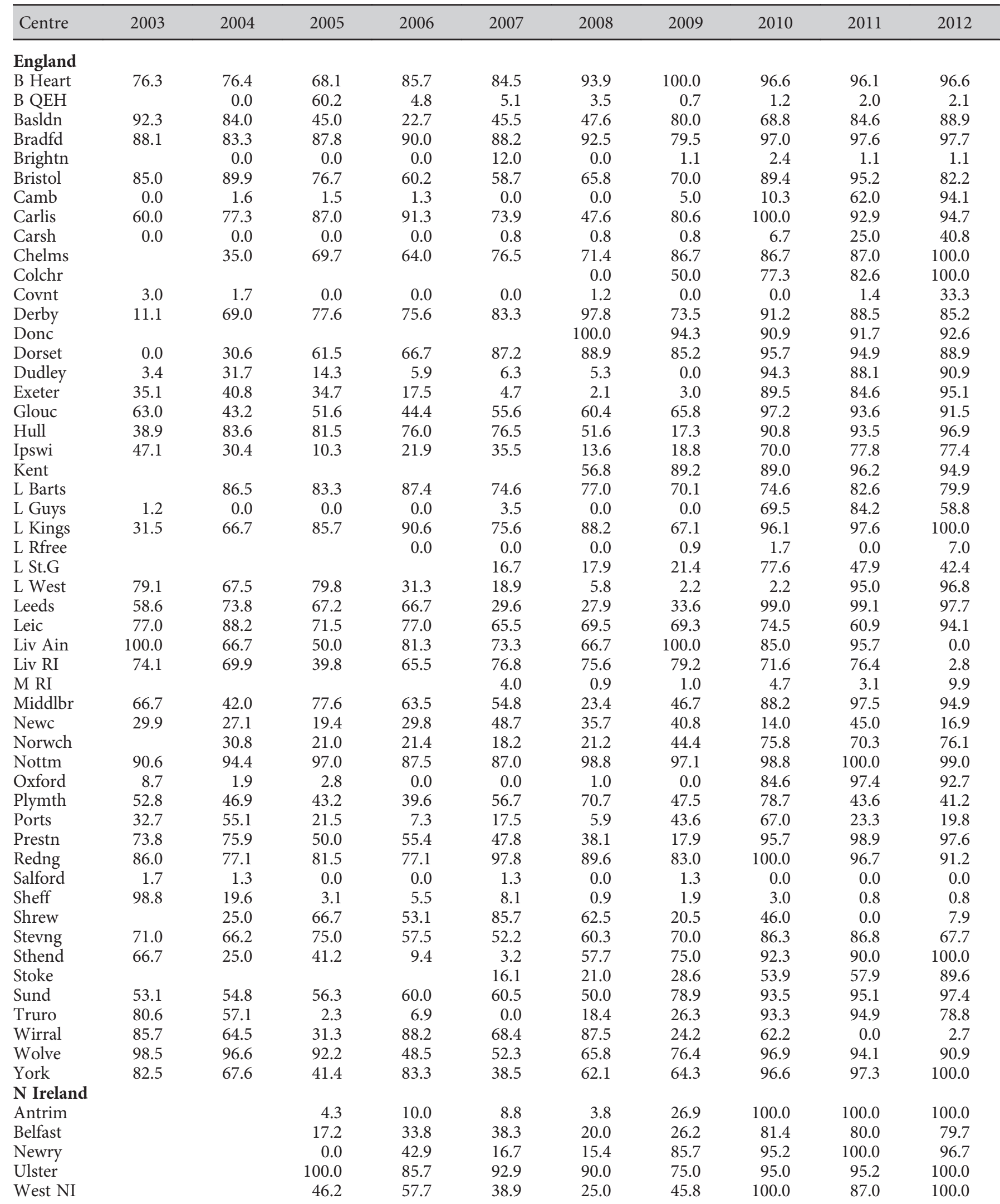


Table 8.19. Continued

\begin{tabular}{|c|c|c|c|c|c|c|c|c|c|c|}
\hline Centre & 2003 & 2004 & 2005 & 2006 & 2007 & 2008 & 2009 & 2010 & 2011 & 2012 \\
\hline \multicolumn{11}{|l|}{ Scotland } \\
\hline Abrdn & 47.7 & 31.7 & 2.8 & 0.0 & 0.0 & 82.9 & 97.6 & 92.1 & 97.6 & 65.7 \\
\hline D \& Gall & 69.2 & 76.9 & 80.0 & 76.9 & 100.0 & 93.3 & 94.1 & 100.0 & 100.0 & 81.3 \\
\hline Dundee & 92.1 & 92.1 & 86.1 & 2.8 & 0.0 & 50.0 & 90.6 & 85.7 & 59.5 & 62.2 \\
\hline Dunfn & 80.0 & 66.7 & 81.3 & 50.0 & 53.8 & 61.9 & 89.3 & 78.6 & 90.0 & 87.5 \\
\hline Inverns & 0.0 & 0.0 & 0.0 & 0.0 & 0.0 & 65.2 & 90.0 & 91.7 & 100.0 & 95.7 \\
\hline Klmarnk & 4.0 & 10.0 & 0.0 & 11.1 & 9.4 & 95.8 & 93.3 & 93.9 & 94.4 & 96.8 \\
\hline Wales & 34.1 & 30.7 & 28.6 & 30.0 & 43.4 & 36.4 & 47.2 & 53.0 & 48.6 & 50.3 \\
\hline Bangor & 39.1 & 42.1 & 66.7 & 35.0 & 86.2 & 52.4 & 76.9 & 73.9 & 90.0 & 100.0 \\
\hline Cardff & 3.5 & 2.6 & 3.5 & 2.2 & 4.1 & 0.0 & 1.6 & 6.0 & 7.9 & 0.6 \\
\hline Clwyd & 22.2 & 0.0 & 0.0 & 11.1 & 45.5 & 84.2 & 83.3 & 100.0 & 85.7 & 89.5 \\
\hline Scotland & 50.5 & 42.5 & 40.3 & 32.3 & 33.5 & 75.2 & 92.5 & 83.8 & 93.1 & 89.1 \\
\hline Wales & 34.1 & 30.7 & 28.6 & 30.0 & 43.4 & 36.4 & 47.2 & 53.0 & 48.6 & 50.3 \\
\hline UK & 50.5 & 49.2 & 44.2 & 39.2 & 36.8 & 39.3 & 43.4 & 61.2 & 66.1 & 66.3 \\
\hline
\end{tabular}

Blank cells denote data not available for that year

Table 8.20. Cause of death in the first 90 days for incident patients by age group, 2000-2011 cohort

\begin{tabular}{|c|c|c|c|c|c|c|}
\hline \multirow[b]{2}{*}{ Cause of death } & \multicolumn{2}{|c|}{ All age groups } & \multicolumn{2}{|c|}{$<65$ years } & \multicolumn{2}{|c|}{65 years } \\
\hline & $N$ & $\%$ & $N$ & $\%$ & $N$ & $\%$ \\
\hline Cerebrovascular disease & 120 & 5 & 25 & 5 & 95 & 5 \\
\hline Infection & 416 & 17 & 76 & 14 & 340 & 18 \\
\hline Malignancy & 216 & 9 & 65 & 12 & 151 & 8 \\
\hline Uncertain & 95 & 4 & 16 & 3 & 79 & 4 \\
\hline Total & 2,412 & & 525 & & 1,887 & \\
\hline No cause of death data & 2,537 & 51 & 555 & 51 & 1,982 & 51 \\
\hline
\end{tabular}

Table 8.21. Cause of death in 1 year after 90 days for incident patients by age group, 2000-2011 cohort

\begin{tabular}{|c|c|c|c|c|c|c|}
\hline Cause of death & \multicolumn{2}{|c|}{ All age groups } & \multicolumn{2}{|c|}{$<65$ years } & \multicolumn{2}{|c|}{65 years } \\
\hline Cerebrovascular disease & 228 & 5 & 60 & 5 & 168 & 5 \\
\hline Infection & 804 & 18 & 226 & 18 & 578 & 18 \\
\hline Malignancy & 460 & 10 & 155 & 13 & 305 & 10 \\
\hline Uncertain & 232 & 5 & 73 & 6 & 159 & 5 \\
\hline Total & 4,390 & & 1,225 & & 3,165 & \\
\hline No cause of death data & 4,430 & 50.2 & 1,255 & 50.6 & 3,175 & 50.1 \\
\hline
\end{tabular}


Table 8.22. Cause of death in prevalent RRT patients by modality, 2011 cohort

\begin{tabular}{|c|c|c|c|c|c|c|}
\hline \multirow[b]{2}{*}{ Cause of death } & \multicolumn{2}{|c|}{ All modalities } & \multicolumn{2}{|c|}{ Dialysis } & \multicolumn{2}{|c|}{ Transplant } \\
\hline & $N$ & $\%$ & $N$ & $\%$ & $N$ & $\%$ \\
\hline Cerebrovascular disease & 135 & 5 & 118 & 5 & 17 & 4 \\
\hline Infection & 532 & 18 & 437 & 17 & 95 & 23 \\
\hline Malignancy & 292 & 10 & 208 & 8 & 84 & 20 \\
\hline Uncertain & 245 & 8 & 212 & 8 & 33 & 8 \\
\hline Total & 2,986 & & 2,576 & & 410 & \\
\hline No cause of death data & 1,414 & 32 & 1,160 & 31 & 254 & 38 \\
\hline
\end{tabular}

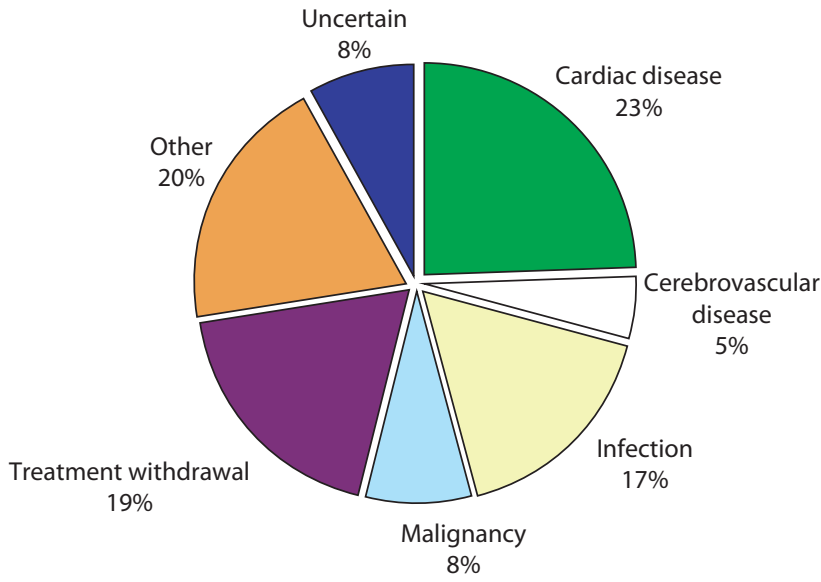

Fig. 8.29. Percentage contribution to cause of death for prevalent dialysis patients, 2011 cohort

chapter. Figure 8.32 shows median life expectancy on RRT after 90 days by age group. All incident patients starting RRT from 2000 to 2009 have been included in this analysis and patients were followed up for a minimum of three years. The estimated median survival will

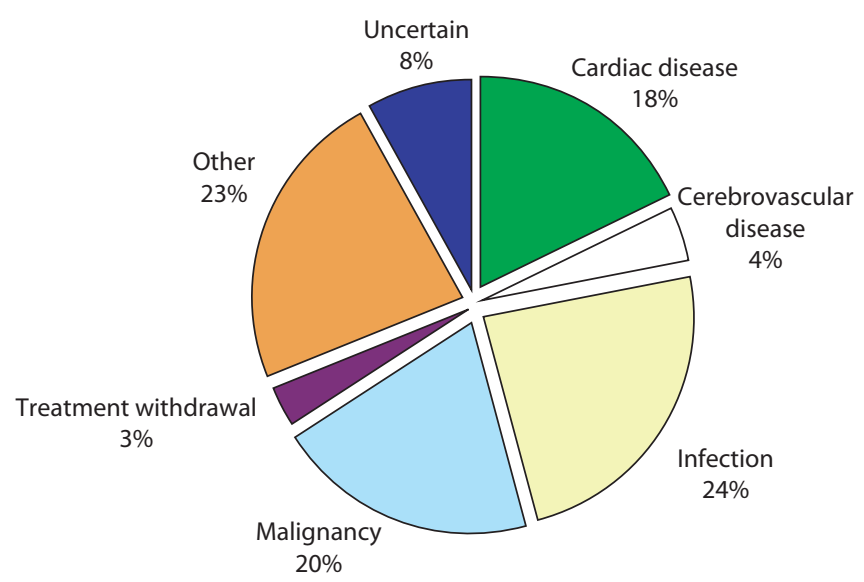

Fig. 8.30. Percentage contribution to cause of death for prevalent transplant patients, 2011 cohort

be different for low risk patients (e.g. polycystic kidney disease with a transplant) vs. high risk patients (diabetes with previous myocardial infarction on dialysis) even within the same age group. Median life years remaining for non-diabetic and diabetic patients (figure 8.33) were

Table 8.23. Cause of death in prevalent transplanted patients by age group, 2011 cohort

\begin{tabular}{|c|c|c|c|c|c|c|}
\hline \multirow[b]{2}{*}{ Cause of death } & \multicolumn{2}{|c|}{ All age groups } & \multicolumn{2}{|c|}{$<65$ years } & \multicolumn{2}{|c|}{65 years } \\
\hline & $N$ & $\%$ & $N$ & $\%$ & $N$ & $\%$ \\
\hline Cardiac disease & 72 & 18 & 36 & 18 & 36 & 17 \\
\hline Cerebrovascular disease & 17 & 4 & 8 & 4 & 9 & 4 \\
\hline Infection & 95 & 23 & 48 & 24 & 47 & 22 \\
\hline Malignancy & 84 & 20 & 42 & 21 & 42 & 20 \\
\hline Treatment withdrawal & 13 & 3 & 5 & 3 & 8 & 4 \\
\hline Other & 96 & 23 & 43 & 22 & 53 & 25 \\
\hline Uncertain & 33 & 8 & 16 & 8 & 17 & 8 \\
\hline Total & 410 & & 198 & & 212 & \\
\hline No cause of death data & 254 & 38 & 126 & 39 & 128 & 38 \\
\hline
\end{tabular}


Table 8.24. Cause of death in prevalent dialysis patients by age group, 2011 cohort

\begin{tabular}{|c|c|c|c|c|c|c|}
\hline \multirow[b]{2}{*}{ Cause of death } & \multicolumn{2}{|c|}{ All age groups } & \multicolumn{2}{|c|}{$<65$ years } & \multicolumn{2}{|c|}{65 years } \\
\hline & $N$ & $\%$ & $N$ & $\%$ & $N$ & $\%$ \\
\hline Cardiac disease & 575 & 22 & 172 & 28 & 403 & 21 \\
\hline Cerebrovascular disease & 118 & 5 & 32 & 5 & 86 & 4 \\
\hline Infection & 437 & 17 & 105 & 17 & 332 & 17 \\
\hline Malignancy & 208 & 8 & 45 & 7 & 163 & 8 \\
\hline Treatment withdrawal & 498 & 19 & 59 & 10 & 439 & 22 \\
\hline Other & 528 & 21 & 143 & 23 & 385 & 20 \\
\hline Uncertain & 212 & 8 & 58 & 9 & 154 & 8 \\
\hline Total & 2,576 & & 614 & & 1,962 & \\
\hline No cause of death data & 1,160 & 31 & 331 & 35 & 829 & 30 \\
\hline
\end{tabular}

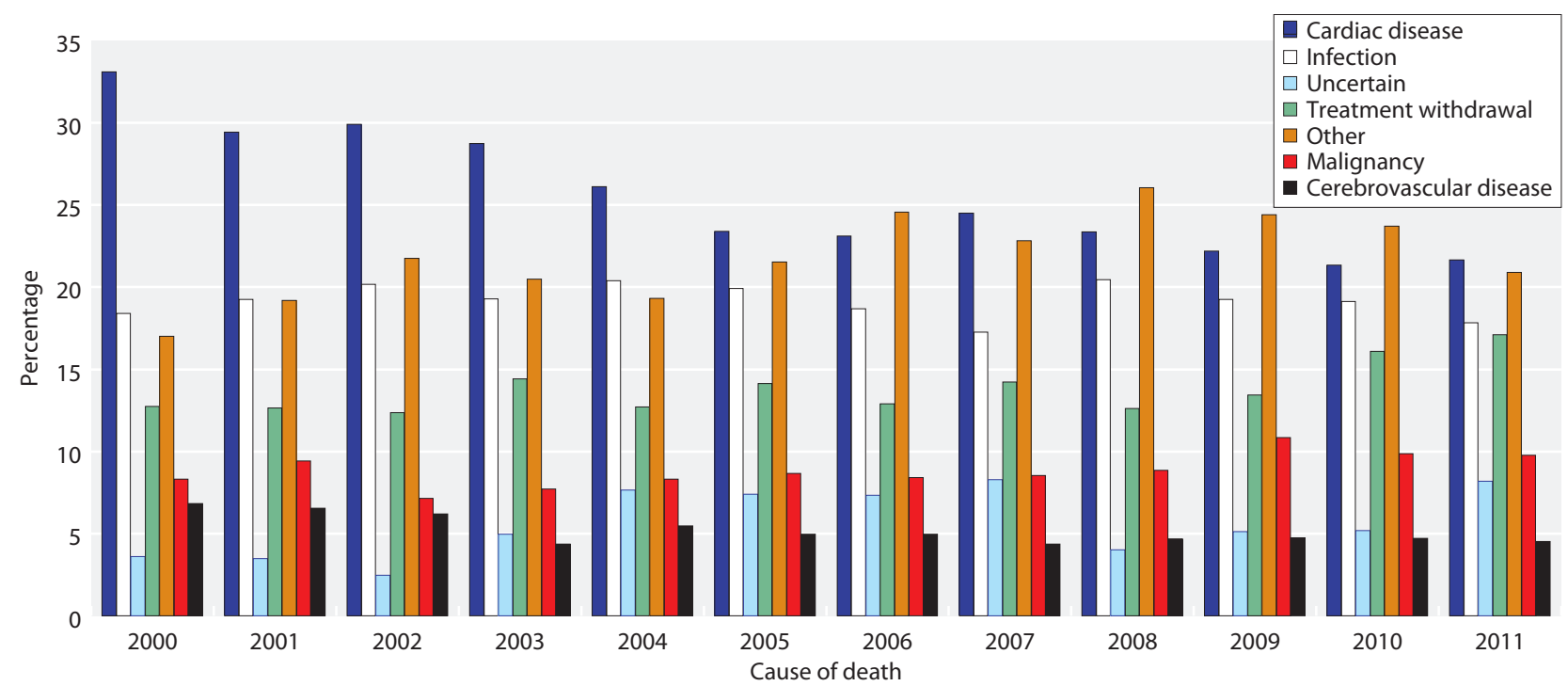

Fig. 8.31. Cause of death in prevalent RRT patients by cohort year

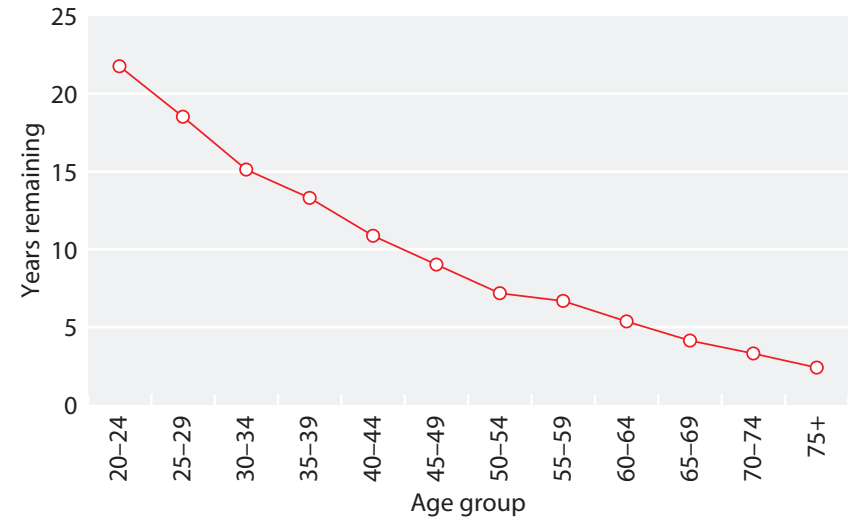

Fig. 8.32. Median life expectancy on RRT after 90 days, by age group, incident patients starting RRT from 2000-2009

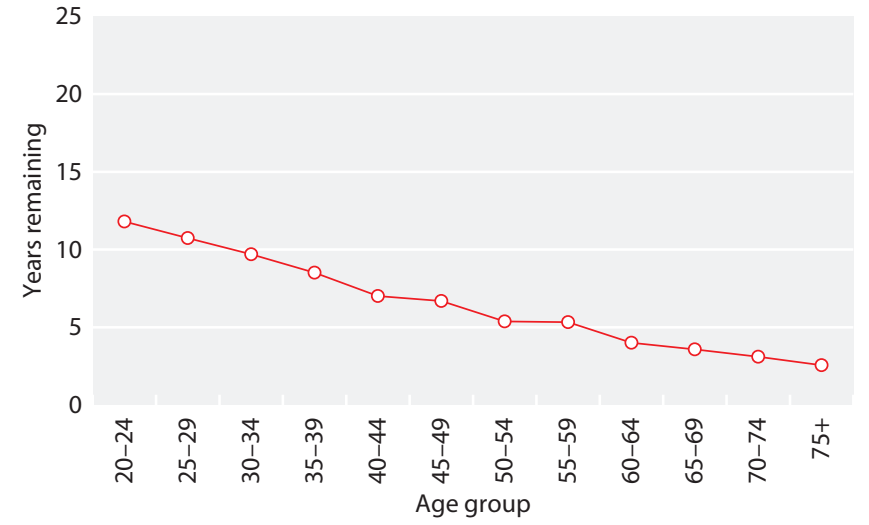

Fig. 8.33. Median life expectancy on RRT after 90 days by age group, incident diabetic patients starting RRT from 2000-2009 
also calculated and show that median life expectancy for patients younger than 45 was on average nine years more for non-diabetic patients (data not shown) compared with age matched diabetic patients. In the older age group (65 years) the median life years remaining were similar between diabetic and non-diabetic patients.

Conflicts of interest: none

\section{References}

1 Plantinga LC, Fink NE, Levin NW, et al. Early, Intermediate, and LongTerm Risk Factors for Mortality in Incident Dialysis Patients: The Choices for Healthy Outcomes in Caring for ESRD (CHOICE) Study. American journal of kidney diseases: the official journal of the National Kidney Foundation 2007;49(6):831-40

2 Miskulin DC, Meyer KB, Martin AA, et al. Comorbidity and its change predict survival in incident dialysis patients. American journal of kidney diseases: the official journal of the National Kidney Foundation 2003;41(1):149-61

3 Nitsch D, Burden R, Steenkamp R, Ansell D, Byrne C, Caskey F, et al. Patients with diabetic nephropathy on renal replacement therapy in England and Wales. Qjm-an International Journal of Medicine. 2007 Sep;100(9):551-60

4 Roderick P, Byrne C, Casula A, Steenkamp R, Ansell D, Burden R, et al. Survival of patients from South Asian and Black populations starting renal replacement therapy in England and Wales. Nephrology Dialysis Transplantation. 2009 Dec;24(12):3774-82

$\checkmark 5$ Tomson C, Maggs C. UK Renal Registry 12th Annual Report (December 2009): Chapter 2: introduction. Nephron Clin Pract. 2010;115(suppl 1): c3-8

6 Ford DJ, Fogarty DG, Steenkamp R, Tomson CRV, Ben-Shlomo Y, Ansell D. Chapter 13: The UK Renal Registry Advanced CKD Study: frequency of incorrect reporting of date of start of RRT. Nephron Clinical Practice;115(suppl 1):c271-c78

7 Malek SK, Keys BJ, Kumar S, Milford E, Tullius SG. Racial and ethnic disparities in kidney transplantation. Transplant International 2011;24(5):419-24 doi: 10.1111/j.1432-2277.2010.01205.x[published Online First: Epub Date]

8 Office for National Statistics. www.ons.gov.uk, http://www.ons.gov.uk/ ons/dcp171778_238743.pdf

$\checkmark 9$ Ansell D, Roderick P, Hodsman A, Ford D, Steenkamp R, Tomson C. UK Renal Registry 11th Annual Report (December 2008): Chapter 7 Survival and cause of death of UK adult patients on renal replacement therapy in 2007: national and centre-specific analyses. Nephron Clin Pract. 2009;111(suppl 1):c113-39

10 van Manen JG, van Dijk PCW, Stel VS, Dekker FW, Cleries M, Conte F, et al. Confounding effect of comorbidity in survival studies in patients on renal replacement therapy. Nephrology Dialysis Transplantation. 2007; 22(1):187-95.

11 Renal Association. Clinical Practice Guidelines. 5th edition. 2010; http:// www.renal.org/Clinical/GuidelinesSection/Guidelines.aspx 


\section{Appendix 1: Survival tables}

Table 8.25. One-year after 90 -day incident survival percentage by centre, 2011 cohort, unadjusted and adjusted to age 60

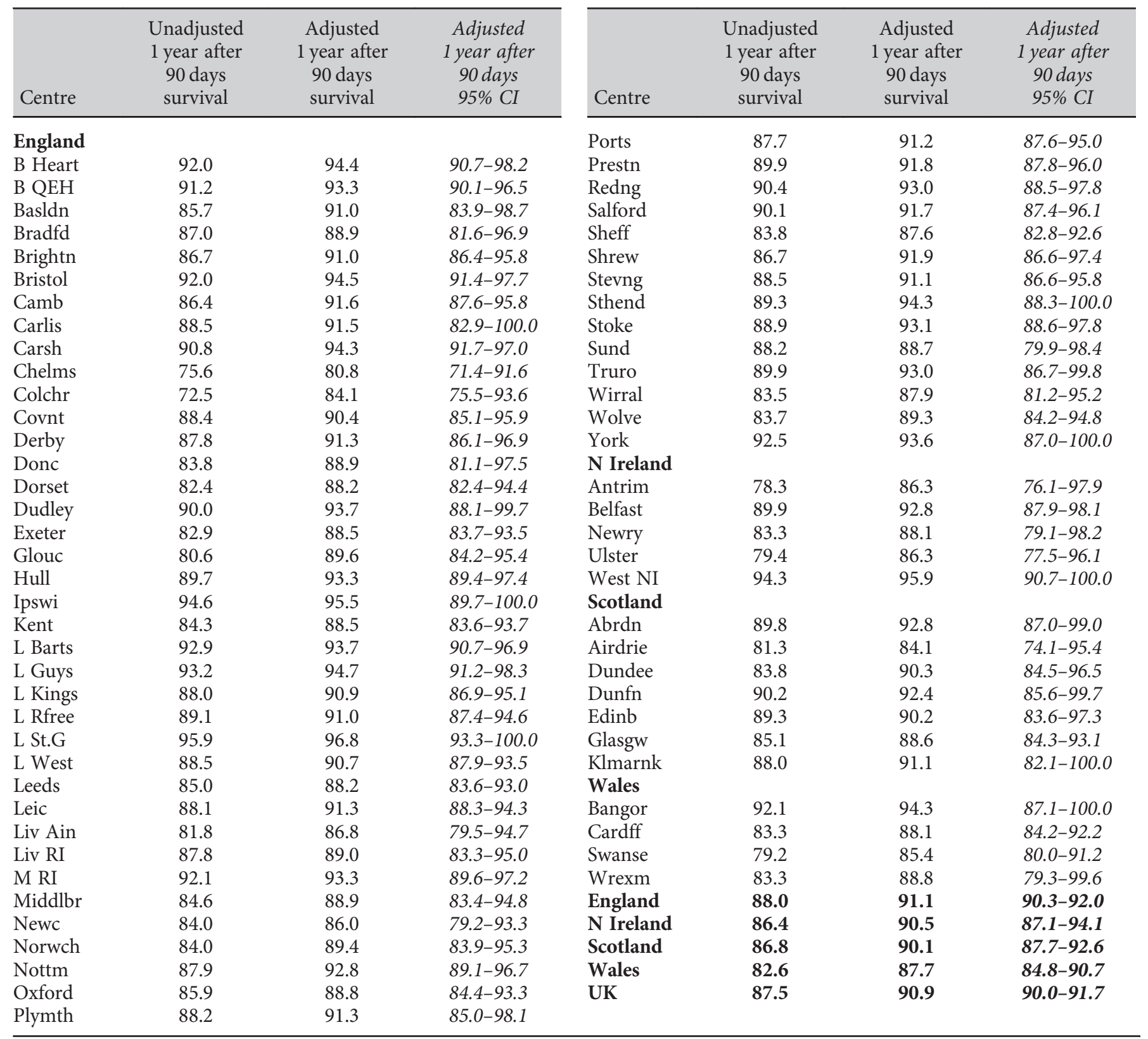

Excluded: centres with less than 20 patients (Clwyd, Dumfries \& Galloway, Inverness) 
Table 8.26. Ninety day incident survival percentage by centre, 2011 cohort, unadjusted and adjusted to age 60

\begin{tabular}{|c|c|c|c|c|c|c|c|}
\hline Centre & $\begin{array}{c}\text { Unadjusted } \\
90 \text { day survival }\end{array}$ & $\begin{array}{c}\text { Adjusted } \\
90 \text { day survival }\end{array}$ & $\begin{array}{c}\text { Adjusted } \\
\text { 90 day 95\% CI }\end{array}$ & Centre & $\begin{array}{c}\text { Unadjusted } \\
90 \text { day survival }\end{array}$ & $\begin{array}{c}\text { Adjusted } \\
90 \text { day survival }\end{array}$ & $\begin{array}{c}\text { Adjusted } \\
90 \text { day } 95 \% \text { CI }\end{array}$ \\
\hline England & & & & Ports & 95.4 & 97.0 & $94.9-99.1$ \\
\hline B QEH & 95.9 & 97.0 & $95.0-99.1$ & Redng & 91.3 & 94.2 & $90.4-98.2$ \\
\hline Basldn & 97.2 & 98.4 & $95.4-100.0$ & Salford & 94.3 & 95.5 & $92.6-98.6$ \\
\hline Bradfd & 93.2 & 94.5 & 89.4-99.9 & Sheff & 93.8 & 95.8 & $93.1-98.5$ \\
\hline Camb & 96.0 & 97.7 & $95.6-99.7$ & Sthend & 96.6 & 98.3 & $95.0-100.0$ \\
\hline Carlis & 96.4 & 97.5 & $92.8-100.0$ & Stoke & 92.3 & 95.5 & $92.1-99.1$ \\
\hline Carsh & 93.6 & 96.3 & $94.4-98.4$ & Sund & 95.7 & 96.0 & $90.9-100.0$ \\
\hline Chelms & 90.0 & 93.6 & $88.3-99.1$ & Truro & 91.1 & 94.3 & $89.2-99.8$ \\
\hline Colchr & 97.4 & 98.7 & $96.2-100.0$ & Wirral & 91.0 & 94.0 & $89.4-98.8$ \\
\hline Covnt & 88.9 & 91.9 & $87.5-96.4$ & Wolve & 93.5 & 96.1 & $93.2-99.2$ \\
\hline Exeter & 94.9 & 96.9 & $94.5-99.4$ & Newry & 96.8 & 98.0 & $94.4-100.0$ \\
\hline Glouc & 95.4 & 97.8 & $95.4-100.0$ & Ulster & 94.4 & 96.6 & $92.1-100.0$ \\
\hline Hull & 92.4 & 95.4 & $92.3-98.6$ & West NI & 97.2 & 98.2 & $94.8-100.0$ \\
\hline Kent & 94.3 & 96.1 & $93.3-99.0$ & Scotland & & & \\
\hline L Barts & 97.7 & 98.1 & $96.5-99.8$ & Abrdn & 94.2 & 96.2 & $92.0-100.0$ \\
\hline L Guys & 97.6 & 98.2 & $96.3-100.0$ & Airdrie & 97.6 & 98.0 & $94.4-100.0$ \\
\hline L Kings & 97.3 & 98.1 & $96.2-100.0$ & Dundee & 93.3 & 96.3 & $92.8-99.9$ \\
\hline L Rfree & 96.2 & 97.2 & $95.3-99.1$ & Dunfn & 89.1 & 91.9 & $85.5-98.9$ \\
\hline L St.G & 96.1 & 97.0 & $93.8-100.0$ & Edinb & 95.7 & 96.4 & $92.4-100.0$ \\
\hline L West & 96.6 & 97.5 & $96.1-98.9$ & Glasgw & 93.4 & 95.3 & $92.7-98.1$ \\
\hline Leeds & 93.6 & 95.4 & $92.6-98.2$ & Klmarnk & 78.1 & 85.5 & $76.3-95.9$ \\
\hline Oxford & 94.6 & 96.1 & $93.6-98.6$ & UK & 94.5 & 96.3 & $95.8-96.8$ \\
\hline Plymth & 96.2 & 97.4 & $94.0-100.0$ & & & & \\
\hline
\end{tabular}

Excluded: centres with less than 20 patients (Clwyd, Dumfries \& Galloway, Inverness) and centres with no deaths recorded in the first 90 days of RRT (Ipswich and Bangor) 
Table 8.27. One year after 90-day incident survival by centre for incident cohort years 2003-2011 adjusted to age 60

\begin{tabular}{|c|c|c|c|c|c|c|c|c|c|}
\hline Centre & 2003 & 2004 & 2005 & 2006 & 2007 & 2008 & 2009 & 2010 & 2011 \\
\hline B Heart & 88.2 & 86.4 & 83.6 & 88.5 & 93.5 & 93.6 & 84.3 & 92.0 & 94.4 \\
\hline Basldn & 92.6 & 92.3 & 92.8 & 90.9 & 89.9 & 89.3 & 88.5 & 84.8 & 91.0 \\
\hline Bradfd & 88.3 & 80.9 & 86.1 & 80.8 & 84.2 & 84.4 & 92.4 & 87.6 & 88.9 \\
\hline Brightn & & 90.6 & 84.3 & 87.2 & 94.2 & 89.3 & 84.7 & 88.3 & 91.0 \\
\hline Camb & 89.4 & 86.9 & 89.8 & 90.9 & 93.4 & 91.2 & 87.7 & 89.5 & 91.6 \\
\hline Carlis & 82.5 & 86.9 & 79.5 & 89.9 & 96.5 & 87.8 & 71.5 & 86.3 & 91.5 \\
\hline Carsh & 89.4 & 85.8 & 90.2 & 88.7 & 87.2 & 86.6 & 88.0 & 89.8 & 94.3 \\
\hline Chelms & & 82.2 & 82.8 & 94.3 & 86.6 & 90.8 & 93.4 & 85.6 & 80.8 \\
\hline Colchr & & & & & & 86.6 & 84.6 & 96.8 & 84.1 \\
\hline Covnt & 81.8 & 87.6 & 82.5 & 88.6 & 90.4 & 86.9 & 94.2 & 89.0 & 90.4 \\
\hline Exeter & 82.3 & 88.5 & 86.1 & 88.9 & 86.4 & 87.0 & 88.5 & 95.3 & 88.5 \\
\hline Glouc & 82.9 & 83.4 & 95.1 & 89.7 & 87.0 & 94.3 & 90.1 & 92.3 & 89.6 \\
\hline Hull & 89.3 & 88.8 & 85.7 & 93.6 & 89.8 & 85.4 & 88.9 & 88.0 & 93.3 \\
\hline Ipswi & 93.2 & 97.4 & 84.4 & 93.9 & 96.0 & 95.8 & 91.3 & 93.2 & 95.5 \\
\hline Kent & & & & & 91.8 & 90.0 & 89.3 & 90.6 & 88.5 \\
\hline L Barts & & 87.1 & 91.0 & 94.0 & 86.5 & 93.1 & 90.1 & 91.9 & 93.7 \\
\hline L Guys & 94.8 & 91.6 & 90.4 & 92.9 & 92.0 & 90.5 & 95.0 & 91.4 & 94.7 \\
\hline L Kings & 88.0 & 86.9 & 91.8 & 86.5 & 87.9 & 89.7 & 86.3 & 89.7 & 90.9 \\
\hline L Rfree & & & 93.3 & 89.8 & 94.4 & 95.2 & 88.6 & 90.3 & 91.0 \\
\hline L St.G & & & & & 92.1 & 94.0 & 92.2 & 93.7 & 96.8 \\
\hline L West & 95.9 & 92.4 & 94.4 & 92.8 & 92.9 & 94.5 & 93.8 & 88.8 & 90.7 \\
\hline Norwch & & 84.0 & 90.7 & 86.4 & 91.1 & 89.0 & 92.0 & 92.1 & 89.4 \\
\hline Nottm & 85.9 & 85.6 & 86.9 & 92.0 & 90.0 & 91.1 & 88.6 & 93.5 & 92.8 \\
\hline Oxford & 89.4 & 87.8 & 87.8 & 90.2 & 89.3 & 87.1 & 91.0 & 90.6 & 88.8 \\
\hline Plymth & 84.0 & 77.7 & 84.5 & 81.2 & 90.1 & 87.8 & 89.9 & 93.8 & 91.3 \\
\hline Ports & 89.8 & 88.4 & 82.4 & 87.6 & 88.7 & 88.8 & 88.9 & 88.1 & 91.2 \\
\hline Prestn & 85.2 & 87.2 & 88.5 & 83.7 & 91.4 & 82.1 & 86.8 & 87.6 & 91.8 \\
\hline Redng & 92.1 & 90.7 & 90.5 & 91.3 & 90.7 & 95.2 & 89.5 & 92.9 & 93.0 \\
\hline Salford & 88.4 & 85.1 & 89.0 & 90.6 & 89.2 & 86.0 & 88.3 & 86.7 & 91.7 \\
\hline Sheff & 87.5 & 91.7 & 90.6 & 88.7 & 90.9 & 92.5 & 93.7 & 92.2 & 87.6 \\
\hline Shrew & & 87.4 & 86.2 & 87.8 & 91.8 & 93.0 & 83.6 & 86.9 & 91.9 \\
\hline Stevng & 93.8 & 93.3 & 76.7 & 85.4 & 90.7 & 90.2 & 96.3 & 93.8 & 91.1 \\
\hline Sthend & 91.8 & 90.4 & 91.1 & 94.9 & 91.8 & 86.5 & 91.2 & 83.0 & 94.3 \\
\hline Stoke & & & & & 87.4 & 89.9 & 85.5 & 87.0 & 93.1 \\
\hline Sund & 80.6 & 86.7 & 80.5 & 83.6 & 88.7 & 85.3 & 79.9 & 84.1 & 88.7 \\
\hline Truro & 86.9 & 92.7 & 90.6 & 89.6 & 90.2 & 89.2 & 93.9 & 90.8 & 93.0 \\
\hline Wirral & 96.6 & 85.5 & 86.9 & 86.0 & 88.9 & 90.4 & 83.9 & 93.0 & 87.9 \\
\hline Wolve & 83.6 & 88.0 & 84.1 & 89.3 & 89.5 & 89.1 & 90.3 & 87.5 & 89.3 \\
\hline York & 76.1 & 91.2 & 83.9 & 82.5 & 95.1 & 86.2 & 93.9 & 86.3 & 93.6 \\
\hline
\end{tabular}


Table 8.27. Continued

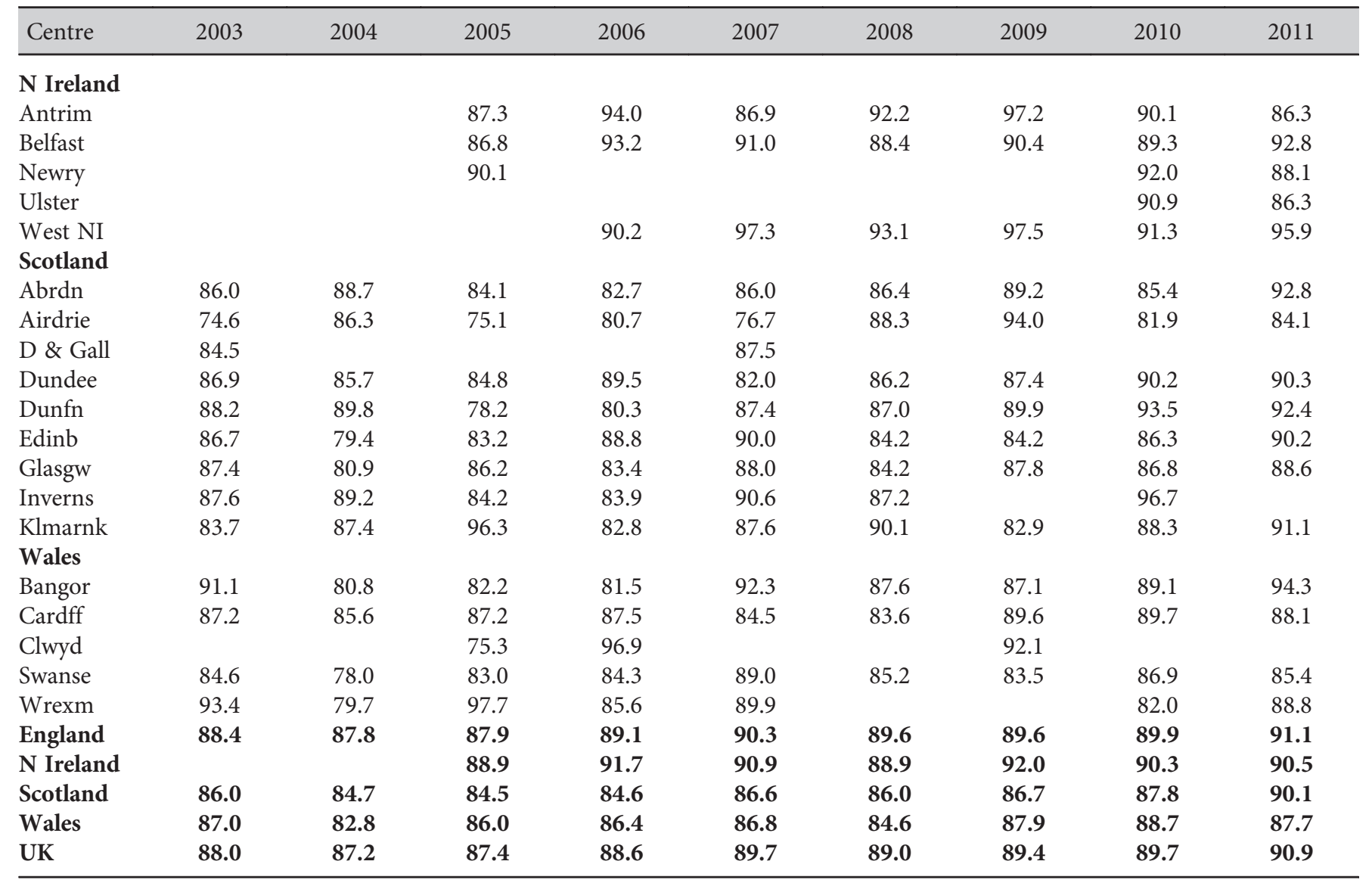

Blank cells: centres with less than 20 patients for that year or centres with no data available for that year 
Table 8.28. One year prevalent patient survival by centre for prevalent cohort years 2002-2011, adjusted to age 60

\begin{tabular}{|c|c|c|c|c|c|c|c|c|c|c|}
\hline Centre & 2002 & 2003 & 2004 & 2005 & 2006 & 2007 & 2008 & 2009 & 2010 & 2011 \\
\hline B Heart & 87.9 & 86.8 & 88.1 & 86.5 & 87.1 & 90.1 & 90.7 & 87.4 & 89.4 & 88.3 \\
\hline Basldn & 84.6 & 87.9 & 90.4 & 90.2 & 90.5 & 92.7 & 91.8 & 88.8 & 91.1 & 88.4 \\
\hline Bradfd & 83.2 & 88.2 & 86.3 & 82.8 & 84.2 & 87.8 & 84.6 & 89.3 & 88.0 & 87.7 \\
\hline Brightn & 99.7 & 87.1 & 84.3 & 87.6 & 87.4 & 89.0 & 87.5 & 90.1 & 88.4 & 89.4 \\
\hline Camb & 87.3 & 88.1 & 87.4 & 89.4 & 88.0 & 92.6 & 90.0 & 91.4 & 93.1 & 88.9 \\
\hline Carlis & 83.4 & 82.9 & 83.7 & 83.8 & 85.7 & 86.9 & 80.2 & 80.4 & 93.2 & 88.8 \\
\hline Carsh & 84.6 & 87.4 & 86.3 & 89.4 & 88.7 & 90.1 & 89.0 & 89.5 & 89.8 & 91.2 \\
\hline Chelms & 98.4 & 86.4 & 82.9 & 85.6 & 87.5 & 85.0 & 86.0 & 89.5 & 84.1 & 90.7 \\
\hline Colchr & & & & & & & 91.0 & 86.5 & 88.9 & 89.1 \\
\hline Covnt & 87.0 & 89.0 & 89.1 & 85.1 & 87.0 & 87.1 & 90.8 & 90.0 & 90.9 & 91.7 \\
\hline Dudley & 85.0 & 86.4 & 85.9 & 87.2 & 87.2 & 88.7 & 88.6 & 90.7 & 87.6 & 91.4 \\
\hline Exeter & 86.9 & 86.2 & 83.7 & 90.9 & 87.1 & 85.3 & 85.3 & 86.5 & 88.2 & 88.0 \\
\hline Glouc & 83.5 & 88.8 & 88.1 & 91.1 & 88.2 & 86.1 & 91.7 & 92.1 & 89.5 & 90.6 \\
\hline Hull & 86.0 & 86.2 & 84.6 & 85.9 & 90.0 & 86.9 & 88.0 & 87.5 & 90.0 & 91.1 \\
\hline Ipswi & 84.8 & 90.2 & 86.0 & 84.5 & 86.5 & 92.7 & 84.8 & 87.8 & 92.0 & 90.4 \\
\hline Kent & & & & & & 86.2 & 87.9 & 90.5 & 89.8 & 89.3 \\
\hline L Barts & & 83.8 & 85.7 & 88.3 & 89.2 & 88.8 & 90.9 & 92.9 & 91.7 & 90.0 \\
\hline L Guys & 88.8 & 88.5 & 89.3 & 87.4 & 90.5 & 90.3 & 91.3 & 91.0 & 93.9 & 91.1 \\
\hline L Kings & 77.7 & 81.1 & 86.7 & 89.2 & 84.9 & 88.0 & 88.0 & 89.4 & 90.1 & 89.9 \\
\hline L Rfree & & & 90.2 & 90.4 & 90.3 & 91.3 & 89.8 & 90.3 & 91.6 & 90.2 \\
\hline L St.G & & & & & 95.8 & 94.3 & 89.2 & 90.8 & 91.9 & 88.5 \\
\hline Norwch & & 87.3 & 88.3 & 90.2 & 87.5 & 91.0 & 89.4 & 89.8 & 91.2 & 91.3 \\
\hline Nottm & 85.3 & 86.7 & 84.7 & 83.4 & 89.5 & 88.4 & 87.9 & 89.7 & 90.1 & 88.9 \\
\hline Oxford & 87.0 & 88.3 & 87.3 & 87.2 & 86.8 & 87.8 & 88.6 & 87.4 & 88.0 & 88.1 \\
\hline Plymth & 84.7 & 85.7 & 87.6 & 83.5 & 82.5 & 87.8 & 85.6 & 85.0 & 89.7 & 84.2 \\
\hline Ports & 82.1 & 89.1 & 85.9 & 85.2 & 89.8 & 88.4 & 89.2 & 88.3 & 88.2 & 89.9 \\
\hline Prestn & 84.8 & 85.6 & 85.8 & 86.3 & 90.7 & 90.1 & 89.7 & 90.1 & 88.1 & 90.6 \\
\hline Redng & 82.7 & 89.2 & 86.2 & 89.0 & 90.6 & 88.8 & 92.3 & 88.8 & 89.3 & 90.8 \\
\hline Salford & 84.4 & 81.8 & 83.6 & 85.9 & 88.0 & 86.5 & 87.9 & 85.2 & 87.7 & 88.9 \\
\hline Sheff & 91.1 & 87.8 & 87.0 & 89.2 & 88.8 & 88.8 & 89.7 & 89.6 & 88.7 & 88.8 \\
\hline Shrew & 94.5 & 84.7 & 86.3 & 86.6 & 89.1 & 88.9 & 87.9 & 85.9 & 87.4 & 89.9 \\
\hline Stevng & 88.6 & 89.5 & 88.7 & 89.5 & 89.7 & 92.4 & 90.4 & 89.9 & 92.7 & 91.9 \\
\hline Sthend & 87.3 & 88.5 & 87.0 & 83.4 & 86.3 & 90.2 & 91.0 & 92.4 & 90.3 & 87.8 \\
\hline Stoke & & & & & 84.5 & 87.3 & 88.5 & 86.8 & 90.9 & 90.6 \\
\hline Sund & 75.5 & 81.8 & 86.4 & 79.4 & 83.7 & 87.5 & 85.2 & 84.7 & 83.7 & 86.4 \\
\hline Truro & 90.3 & 89.9 & 85.1 & 91.8 & 89.3 & 89.4 & 89.0 & 90.7 & 89.0 & 89.6 \\
\hline Wirral & 83.5 & 87.4 & 89.4 & 88.5 & 88.1 & 89.6 & 90.2 & 88.6 & 90.7 & 90.4 \\
\hline Wolve & 85.0 & 87.6 & 86.8 & 89.3 & 87.8 & 92.8 & 89.4 & 87.4 & 89.3 & 88.6 \\
\hline York & 81.1 & 83.0 & 89.4 & 84.0 & 88.5 & 87.9 & 88.8 & 90.0 & 84.1 & 88.6 \\
\hline
\end{tabular}


Table 8.28. Continued

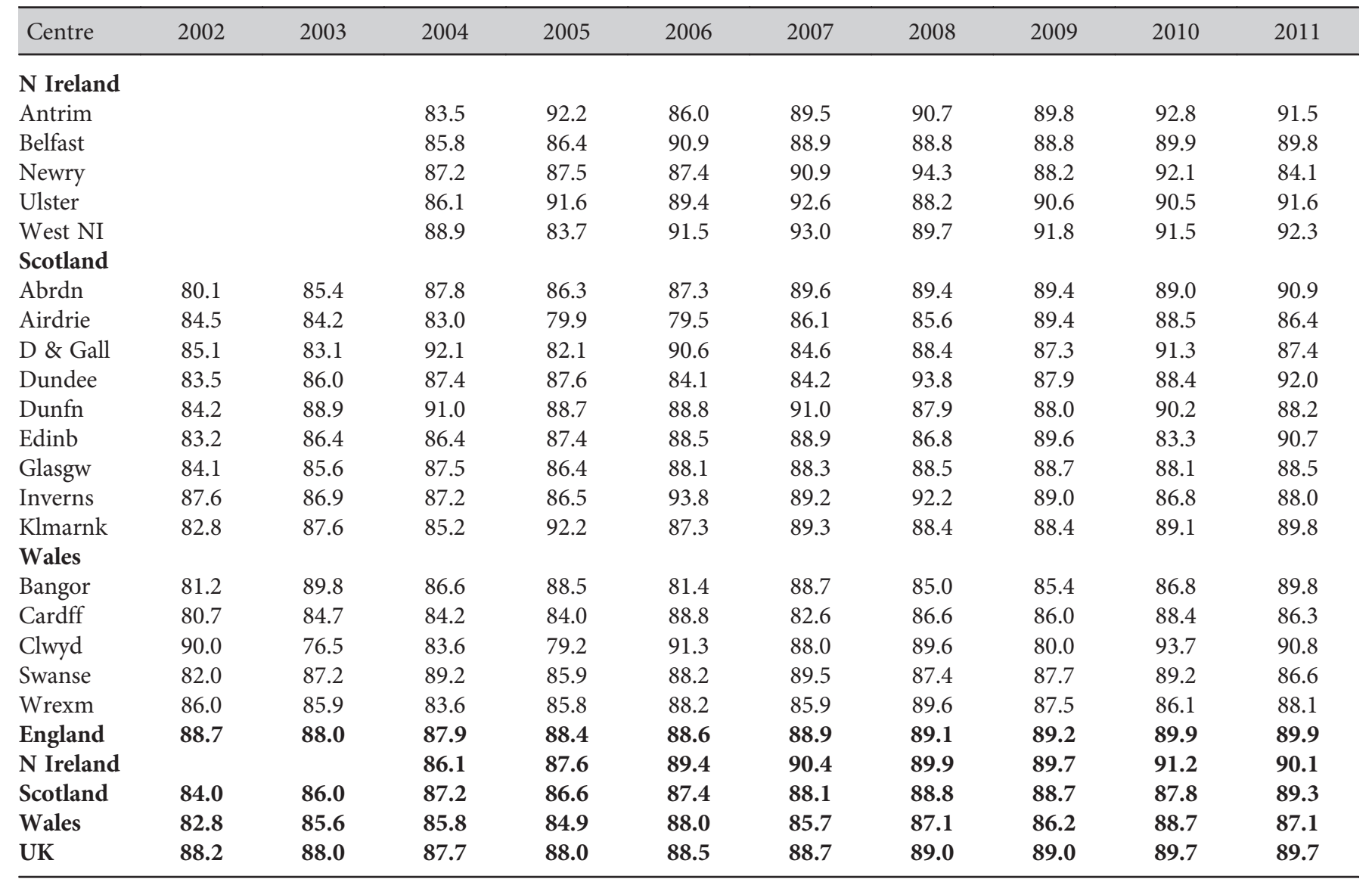

Blank cells: data not reported for that year or less than 20 patients in the year 